\title{
¿Potencias intermedias o países mayores? La política exterior de Argentina, Brasil y México
}

1. MPPACTO DE LA SITUACIÓN INTERNAGIONAL SOBRE LAS RELACIONES INTRARREGIONALES

¿Fasta qué punto el analista de las relaciones internacionales puede clesprenderse de los condicionamientos cle la realidad circundante? ¿Cuán de cierto hay en materia de objetividad?

Las deformaciones más comunes, y a la vez citadas como respuestas, básicamente son dos, ambas en estrecha interrelación. A) Quien contempla el régimen internacional no puede desprenderse de su espíritu "provinciano". Inexorablemente lleva consigo la deformación óptica. El fenómeno "provincialista" - tan común en nuestra América Latina- hace que la imagen percibida se muestre deformada. El fenómeno físico de la refracción tal vez ayude a ejemplificar nuestro aserto. En síntesis, el pensamiento "provinciano" mirará al mundo desde una situación excéntrica. Su "perspecliva" será singular. B) El análisis al que se arriba siempre constituirá una seudofalsificación. Por más que se cleclare -el observador- neutro, ava. lorativo y objetivo, al querer clesentrañar el mundo no cae en la cuenta que lo está mirando descle un ángulo y que, en consecuencia, sus opiniones y juicios no siempre serán correctos. Si a esto se le agrega el grado de excentricidad valorativa, tendremos que concluir precariendo al lector respecto de nuestras propias y eventuales deformaciones.

Pretendemos desentrañar el sentido de los cambios que se observan en el régimen internacional. Trabajamos con categorías $\mathrm{y}^{\prime}$ abstracciones. En medio de toda esta batería conceptual no podemos dejar de reconocer nuestras propias limitaciones: somos habitantes del hemisferio sur y por ende, insuficientemente desarrollados. Somos latinoamericanos; queremos el progreso de nuestros pueblos y naciones; necesitamos aumentar nuestro poder de negociación internacional; luchamos por la justicia internacional; queremos "desfeudalizar" el régimen internacional; propugnamos, en consecuencia, relaciones horizontales en reemplazo de las supeditaciones verticalistas. 
Entre quienes comparten estos supuestos se observa un fenómeno curioso: el mutuo convencimiento. Como antaño la geometría euclidiana deformó la visión del universo, asi el elemento volitivo ha deformado la visión de nuestra realidad contingente. Las características "labilísticas" del pensamiento político del hemisferio sur produjo una singularidad fenomenológica. Mutatis mutandis, el querer ser devino en "ser". Fue tal la fuerza del "querer" que alimentaba el ensoñamiento latinoamericano, que, cuando alguien interponía sus dudas respecto del futuro feliz automáticamente era tachado de antiprogresista.

EI reduccionismo convertido en hábito adquirirá también formas fatalistas. Asi se explican las singularidades ciclicas. Al "tempo" optimista y ufano le sucede otro, pesimista y escéptico. El espiritu latino, $\tan$ rico e imaginativo, pero también inestable e inseguro, es fácil de encandilarse $y^{\prime}$ por los efectos del deslumbre asegurará que el futuro está allí, a su alcance. Cuando al tiempo se cotejan los resultados y éstos no coinciden con el modelo patrón, entonces se entroniza al pesimismo. Nuevamente se vuelve al punto de partida.

Este reciclaje político latinoamericano explicaría el por qué de la endeblez de ciertas políticas y la insustantividad de ciertos análisis. Se cree y se deja de creer; se piensa y se deja de pensar al poco tiempo. Por último la noción del "tempo" resulta estrecha y exitista.

Todo esto viene a colación puesto que calificamos como excesivamente asertóricas ciertas interpretaciones formuladas en materia internacional durante los últimos años y sobre las consecuencias que de ellas se desprenderían respecto de nuestra región. Veamos algunas:

a) Como consecuencia de la finalización de la "guerra fría", el régimen internacional presentaría las características de un sistema multipolar.

b) Como consecuencia de a), las potencias medianas y las pequeñas gozarían de un alto grado de permisibilidad internacional.

c) La detente entre Ios EE. UU. y la URSS pone fin a la competividad ideológica y a la política de las esferas de influencia.

d) Existirían otros polos de poder. Estos polos (Europa, Japón y China Popular) tendrían:

1) Capacidad de clisuasión militar.

2) Sistema económico autónomo.

3) Entre sus objetivos internacionales "descongelar" las relaciones de poder inteinacional.

Está de más decirlo, estas formulaciones atribuyen a los "polos hos- 
Oarlos Pérez Llana / ¿ Potencias intermedias o paises mayores?

tigantes" manifiestos deseos de "horizontalizar" el mundo, planteando a la vez estrategias de cooperación y no de conflicto.

e) Las tendencias internacionales conducirían a la paz -o por lo menos a un grado admisible y administrable de conflictos.

La guerra queda, de suyo, descartada.

f) Los países superdesarrollados están dispuestos -o lo estarán a plazo corto- a reconocer los derechos cle los medianos y pequeños:

g) La tendencia hacia las relaciones horizontales es irreversible.

Todas estas formulaciones $-\mathrm{y}$ las omitidas por razones de espacioposeen un alto grado de veraciclad. Si esto es así, ¿adónde radicaría lo pernicioso de todas ellas?

Recordamos al lector lo que afirmamos a modo introductorio. El mal radicaría en la globalización y en la falta de constatación. De manera que, en vez de ser herramientas eficientes para quien pretenda alcanzar metas y objetivos de cambio (políticas que constituyen un deseo más o menos común en la región), estas formulaciones estariạn obrando de manera inversa. Es decir que constituirían "relos" que ocultarian la visión para quien pretenda operar en una realidad fluida y compleja.

Nuestro propósito es el de ayudar, en la medida de lo posible; a desentrañar las tendencias profundas del régimen internacional, ejercicio previo $y^{\prime}$ necesario para constatar luego la medicla en que ellas nos afectan.

Comparemos críticamente las anteriores formulaciones.

a) ¿Hasta qué punto es útil repetir constantemente que la "guerra fría" ha cesado? Es válido preguntar respecto de las bondades subyacentes del método que consiste en dar por nacidos y muertos a determinados periodos históricos.

Metodológicamente sí es útil la distinción como elemento aclaratorio y la construcción de "estructuras-ideales". También: es :factualmente cierto que las características actuales del régimen inteinacional difieren sustancialmente de las de la década del 50.

Pensamos, sin embargo, que là recurrencia afirmatoria políticamente puede resultar peligrosa en el sentido que podrá confundir al "piloto" cle la política exterior. Lo que ha variado son los métodos.

Nuestro temor radica en el peligro que subyace tras los simplismos. Quien cree que el futuro es ahora más fácil, que las circunstancias internacionales le permitirían..., etc., etc., pondrá menóy atención en lo que ahora aparecería como secundario. La sorpresa vendrá luego, 
cuando intente operar en "la estructura ideal". ¿Acaso la guerra de Yon Kippur no demostró el poder reàl de las superpotencias? ¿Acaso no fue éste un juego de dos a través de terceros?

En sintesis, pensamos que es correcta la imagè de una mayor fluidez internacional. Pero también es cierto que los actores centrales persiguen, hoy más que nunca, una política de fronteras rígidas. ¿Acaso el paradigma de Kissinger, Metternich, no fue un hombre "restaurador"? Y el manejo soviético de la crisis checa y el resurgimiento de la figura de Stalin en la URSS, ¿no nos evocan idéntica imagen?

b) La lógica de la "mayor permisibilidad" parte de los supuestos y de las creencias democratistas fundamentadas éstas en el supuesto del fin de la "guerra fria".

El problema aquí será de "tempos". Es correcta la afirmación que destaca las fracturas y las filtraciones que se producen en el momento del tránsito de una fase a otras (para quienes creen en fases) o de unos métodos y' reglas a otros. Las potencias medias y los pequeños países podrían así aprovecharse de los intersticios que dejan los "grandes". La cuestión radica en saber el tiempo con el que se cuenta para aprovechar y operar en consecuencia. De lo contrario, durante años se pueden anunciar las posibilidades tal como si éstas fueran eternas.

El tiempo corre para todos. Los "débiles" debemos tener en cuenta que así como nosotros conocemos el problema y' llamamos la atención a nuestros gobiernos, también los "fuertes" conocen el tema y tratarán de remedar esa situación en plazos cortos.

Las dimensiones del tiempo no son las de antaño. En consecuencia no podemos jugar a que entre una fase $y$ ' otra, o entre las viejas y las nuevas reglas, mediará un tiempo largo. Justamente, el "fuerte" lo es en tanto y en cuánto está capacitado para administrar conflictos globáles en su propio provecho y rápidamente.

La carencia de la afirmación radica en la falta de encuadie. Es necesario tener presente que lós plażos históricos son prescriptivos. Lo no 'realizado a' su debido tiempo jamảs 'sexá efectuado.

Los "fuertes" también conocen las características de los plazos. Pero ellos tienen "una' véntaja, pueden acortar el plazo. ¿Cómó? Encuadrando verticalmente a quieries. se ubican en su esfera y negociando en la cúspide. Pero pára negociar será necesario algo que afécta sustancialmente a los "çébiles": no pueden admitirse las heterodoxias.

c) En la década de los 50 se anunció la predicción de un mundo futurb a-ideológico. Hubo otras apreciaciones, v.'g. la que predecía 
el fin de las ideologías y, por último, quienes afirmaban la inexorable convergencia de los sistemas capitalistas y socialistas.

En la década de los 60, cuando se producen los primeros acercamientos entre los EE. UU. y la Unión Soviética (hay quienes sostienen que el acercamiento se produce en la década del 50, más concretamente cuando los "grandes" auspician el Tratado Antártico), los hechos son utilizados, por quienes suscribían este tipo de tesis, como datos confirmatorios de las predicciones. Paralelamente también se daba por periclitada la política de las esferas de influencia.

Hoy podemos afirmar que el mundo a-ideológico no existe. Respecto de la convergencia digamos que el aserto peca de reduccionista. Que el capitalismo acepte convivir junto a un Estado no tan neutral y que. la sociedad socialista demande ahora productos sofisticados y/o suntuarios, no necesariamente esto significa que ambos sistemas se hayan cooptado mutuamente.

Lo que realmente se constata son fenómenos comunes que devienen de una cultura común: la industrial. Además, sea cual fuere la estructura productiva, en ambos sistemas se presentan los problemas de la civilización urbana (contaminación, población, recursos, etc.). Entonces es comprensible que en ambos sistemas se observen preocupaciones y conductas semejantes. Ahora bien, deducir la convergencia en base a estos fenómenos no deja de ser un simplismo.

Además, ambos sistemas no han abandonado ninguno dé sus principios. Más aún, ambos siguen creyendo en sus ventajas y en la inexorabilidad de su triunfo. Justamente, como creen en su propio futuro es que no arriesgan su subsistencia a la suerte del holocausto nuclear. Conscientes del empate juegan a clesempatar. Esta es su lógica.

En el complejo esquema de las relaciones bilaterales entre las super: potencias no se descarta ningún tipo de sistema, ni siquiera el de la co-presidencia. Pero tampoco el conflicto. Ambas, a veces optan por "pulsear" y' usan de "bancos de prueba" locales, por ejemplo, los conflictos bélicos comprobarán la calidad de los implementós. propios y la capacidad de los ajenos.

Entre quienes sostienen las tesis de la convergencia con victoria capitalista, es común observar la citá de un ejemplo: el dé las negociaciones entre los países socialistas y algunas empresas transnacionales. Este es un dáto cierto, y hasta ayer impensable. Pero adolece de algunas omisiones el ejemplo.

1. Para los dirigentes socialistas negociar con las transnacionales no es lo mismo que negociar con Estados capitalistás. Para el pensamiento marxista se tratan éstas de un nuevo estadio de la concentración del capital. 
2. La funcionalidad que existió entre los intereses estaduales de occidente y los intereses económicos de las empresas hoy ya no existe. La transnacional tiene su propia lógica, sus propios símbolos y sus propios objetivos. Hasta tiene -según Galthung- sus propios ciudadanos: los Bingos. Los ejemplos que ejemplifican la disfuncionalidad abundan. Sin embargo destacamos dos:

a) Las quejas de los sindicatos de los países "padres" de las transnacionales. Los problemas que ocasionan estas empresas atentan contra estos intereses locales, v. g. no emplearán mano de obra local y los productos fabricados en el extranjero al ser más baratos competirán con los locales.

b) Esto está relacionado al tema de la crisis energética. Occidente percibió que no necesariamente coincidían los intereses nacionales con los de las transnacionales. El senador Jackson (del Subcomité de Investigaciones) recientemente citó a las empresas petrolíferas líderes haciéndoles conocer la preocupación del Senado estadounidense ante un hecho que se constató en el apogeo del embargo árabe: en el último cuatrimestre del pasado año las empresas petroleras aumentaron enormemente sus ganancias (Texaco $70 \%$; Mobil $68 \%$; Exxon 59\%; Unión 55\%; Gities 50\%). Llama la atención la respuesta de las empresas, ella demuestra la singularidad de su lógica que no coincide con la lógica del Estado nacional. En su contestación afirmarán que en una economía de libre mercado la empresa debe obtener el máximo de ganancia, dirán además que ellas habían sido criadas y formadas en esa sociedad (ver TIME, febrero 4, 1974, "Las ganancias del petróleo bajo el fuego").

Un dato de interés, los países de la OPEP coinciden con la preocupación del Senado. Ellos culpan a las empresas de ser las causales de la actual crisis debido a sus enormes ganancias.

3. Los países socialistas negocian con las transnacionales puesto que son conscientes de sus carencias tecnológicas. Esta última no conoce ideologías y es básicamente producida por esas empresas. De manera que es un juego de mutuas conveniencias. También asi se explica la adhesión socialista al Acuerdo de París.

4. ¿Acaso no es mejor negociar con el representante del capitalismo que ostente mayores indices de concentración y de avance científicotécnico?

5. ¿Acaso no es mejor negociar con alguien que no tiene ejércitos y que actualmente, dada la correlación de fuerzas, tampoco se ocupará de pedirlos? 
6. ¿Acaso, ésta no es una forma de jugar a las contradicciones?

Pensamos por último $-y$ sienclo coherentes con a) $y^{\prime}$ b) - que los "fuertes" negocian permanentemente. Pero esto de ninguna manera significa que las esferas cle influencia han clesapareciclo. Se han reaclaptado.

d) La literatura sesentista bien ha clicho que existen otros polos. No poclemos enfrentarnos a la evidencia. En cambio pensamos que es necesario distinguir y proponer algunas dudas.

Hasta la reciente crisis energética era correcto citar a Europa y a Japón como "fuertes". Mas ahora, se puede cuestionar la solidez y la seriedad de estas manifestaciones de heterodoxia. Hasta habrá quienes niegan la espontaneidad de la crisis.

Sucedió que se confundió cierto grado de desarrollo y la bonanza económica por la que atravesaron esos países clurante los 60 (recordemos Ios superavits comerciales de Europa y Japón) con capacidad autonómica. Así las cosas, también se supuso que ya habían llegado esos países a la cúspide de la estratificación internacional.

De la crisis salieron fortalecidos los "más fuertes de los fuertes" y "los más débiles de los débiles". Los "intemedios" corrieron la peor suerte. Entonces, ¿dónde está la capacidad autonómica de los candidatos a "fuertes"?

En materia militar pasará algo similar. No todos los nuevos polos están en capacidad de transformarse en alternativa y mucho menos en interlocutores de los "grandes". Podrán vender material bélico con cierto grado de sofisticación (Mirages, AMX, misiles aire-tierra) pero con la sola excepción cle China Popular (tercera potencia militar descle el momento que ha logrado miniaturizar el explosivo nuclear $y$ posee misiles de alcance intermedio) nadie está en condiciones de defender a terceros de los supuestos ataques cle los "fuertes".

Nos salta también una ducla. ¿Los "polos hostigantes" realmente desean "horizontalizar" el régimen internacional? ¿La política de cooperación, es una táctica o una estrategia?

e) La existencia de una "devaluación del poderío militar", desgra. ciadamente no significa que el reino de la paz esté en nosotros. El empate nuclear no necesariamente equivale al eterno congelamiento del empate.

El modelo de paz implícito en la formulación peca de estático. Supone que no existirán cambios políticos cle magnitud clentro de los "fuertes", ni siquiera en el plazo largo. Supone también el empate en materia de descubrimientos de aquí para siempre. ¿No es posible acaso que en algún momento alguien desempate? 
¿Y si las élites políticas llegan a entrever que pueden obtener ventajas cle un conflicto bélico? ¿Cuán reales son los atributos cle supervivencia de las "palomas"? ¿La prolifexación nuclear no puede reflotar la vieja idea de constituir una "policía nuclear"? ¿Esto último, no originaría conflictos?

f) Los resultados del Decenio del Desarrollo y en general los de la UNCTAD sin duda no han estado a la altura de las expectativas que en ellos habían depositado los países del Tercer Mundo. El Informe Pearson afirmaba: "Sin embargo, en nuestros días el apoyo internacional al desarrollo languidece. En algunos paises ricos se pone en tela de juicio su viabilidad, e incluso su objeto mismo".

Las crisis por las que atraviesan los países ricos y las preocupaciones externas constituyen algunos de los obstáculos para la comprensión de los derechos y de los problemas por los que atraviesan los países más pobres.

Además, el reconocimiento de estos derechos no deja de sex dificultoso para quien observa al munclo desde una perspectiva internacional de fronteras no-flexibles. También atenta contra la capacidad de comprensión la política horizontal cle los países pobres. En el Discurso ante la Asamblea de la ONU el Secretario de Estado norteamericano, H. Kissinger afirmó: "La organización de un grupo de países (los 'débiles') propietarios de recursos en formas de bloque (¿la OPEP?) ¿producirá, tarde o temprano, la organización de las posibles víctimas ('los fuertes'?) como una especie de contrabloque?... La política de recurrir a la presión y a las amenazas socavará la base interna de este apoyo ('la ayuda a los países en rías de desarrollo')".

g) La horizontalización no se trata de una tendencia irreversible. Las relaciones horizontales constituyen una de las vías con que cuentan los países pequeños y medianos para incrementar su poder de negociación internacional, aumentar su capacidad de endogenia e introducir los ajustes que creen necesarios dentro de sus estructuras societales. Diríamos que estamos frente a una tendencia auspiciosa. Sin duda alguna, la política horizontalista constituye uno de los más importantes mecanismos cle "la batería autonomizante" que poseen los "débiles". Desde la CIPEC hasta la OPEP el mundo emergente ha aprendido una rica y dura experiencia.

Sin embargo el peligro que anotamos consiste en la idealización de este tipo de estructuras. No siempre querer es igual a poder. Los obstáculos con los que se ha enfrentado el proyecto UPEB (países exportadores de bananas) hasta la ruptura de la unanimidad en la OPEP (en la reciente reunión de Quito, Arabia Saudita rompió el 
mecanismo implícito del consenso en el tema referido a la política impositiva) nos debe llamar a la reflexión.

Sólo se trata de un toque de atención, no necesariamente esto implica una actitud pesimista. Tal vez esto demuestre que el acuerdo no está en la naturaleza de las cosas. Se lo debe buscar - a lo mejor más lentamente de lo deseado- siempre descle una perspectiva solidarista y de largo plazo. No se debe caer en el desconocimiento -propio del pensamiento "provinciano"- de aquello que no nos" gusta pero que, sin embargo, existe: las tendencias verticalistas del régimen internacional.

BRASIL - ANTECEDENTES HISTÓRICOS

La audacia y el dinamismo, características sobresalientes de la política exterior brasileña, iconstituyen un fenómeno novedoso o se trata de la resultante de una tradición históxica rica en experiencias y desafíos?

Sin duda esta pregunta ha sido repetidamente formulada por los observadores y analistas del subsistema latinoamericano. Es más, Brasil comúnmente es citado como el ejemplo tal vez más acabado de una conducta internacional definida y consecuente.

Nos retrotraeremos entonces a las fuentes históricas con el solo objeto de detectar y acompañar el desarrollo de las tendencias profundas de la política exterior brasileña.

Brasil será el primer país de la región que experimentará el autogobierno. En los restantes países de la región será la invasión napoleónica u otros factores - más tardios- quienes obrarán a manera de catalizadores al obligar a las élites locales al ejercicio de la administración estadual.

La ocupación de la metrópoli portuguesa en manos de España ${ }^{1}$ da la oportunidad a la élite brasileño-portuguesa y/o criolla de ejercitarse en las funciones gubernativas. Serán 60 años de autogobierno. Mientras tanto, el resto de América Latina se encontraba en el apogeo de la subordinación colonial.

Esta experiencia originará importantes consecuencias. El grupo local que accede a Ias tareas de gobierno adquirirá rápidamente conciencia de su capacidad y eficiencia. Se establece también la distinción entre el "nosotros" y el "ellos" y, sobre todo, la élite brasileña en contacto directo con el aparato administrativo estará en condi-

IPara las implicancias políticas de esta ocupación, ver, Helio' Jaguaribe, "Desarrollo Económico y Desarrollo Político", Eudeba, Buenos Aires, 1968. 
ciones de juzgar a la aclministración colonial en función de la relación costo-beneficio. Resultó entonces indudable que los costos que insumía el mantenimiento de la élite colonial no estaban en relación con los servicios que ella brindaba. ${ }^{2}$

Siempre desde la perspectiva de la autoconciencia de la élite local, no debe desconocerse las consecuencias del fiscalismo - mercantilistade la corte lusitana. La exacción fiscal originará numerosos conflictos durante el ciclo azucarero y, más aún, durante el ciclo mineralífero en donde la relación productor local v.s. "colonialismo extractor" adquirirá la forma de abiertos enfientamientos.

La ocupación hispana originaría también otras implicancias. Al apoyar Inglaterra a la corona portuguesa en su lucha contra el invasor conseguixá, a cambio, privilegios de todo tipo, preferentemente comerciales. El Acuerdo de Methuen (1703) permitirá a Inglaterra introducir sus productos en el mercado luso-brasileño. De allí en más Brasil mantendrá vínculos cuasi-directos con la corona inglesa.

De manera que el Brasil se adelantará históricamente -respecto del resto de la región - al enfrentarse con clos experiencias: la necesidad de autogobernarse $\mathrm{y}^{\prime}$ la apertura que realiza respecto cle Inglaterra. Esto último, que para la mayoría de los países de la región revistirá características traumáticas, permitió al Brasil revalorizarse - frente a sí y frente a los demás- y gozar, tempranamente, de las ventajas de una dependencia racionalizada en términos más o menos operativos.

$\mathrm{Si}$ bien es correcta la distinción que se formula entre nacionalismo y "nativismo", resulta sugestiva la coincidencia, respecto de algunos temas, en la formulación de ambos "ismos". El "nativismo" exaltaba la magnitud del territorio, las riquezas y' el futuro promisorio que le aguardaba al Brasil. Algunas de estas ideas tno son constituyentes del nacionalismo contemporáneo? ¿Acaso los elementos que el "nativismo" exalta no se asemejan a los argumentos en base a los cuales sería factible el logro de un status de "potencia intermedia"?

La opción -por lo demás inevitable- por una "dependencia racionalizada" tno devino en sustituto respecto de la ya agotada relación colonial? A manera de hipótesis adelantaremos algunas implicancias que consideramos de interés y que se deducen de estos hechos.

a) La temprana presencia inglesa facilitará la ruptura de la cerrada madeja de intereses comerciales preexistente.

2Sobre el tema de la funcionalidad de las élites, ver, Helio Jaguaribe, "Desarrollo politico: Sentido y condiciones", Paidós, Buenos Aires, 1972.

3Ver, Helio Jaguaribe, "La dinámica del nacionalismo brasileño" en "Obstáculos para la transformación de América Latina". Compilado por Claudio Véliz, F. C. E., México, 1969. 
b) Brasil se vinculará directa y tempranamente con el país que luego se convertirá en la potencia económica.

c) Brasil poclrá apartarse fácticaménle - todavía no formalmentede todo lo negativo del quietismo tradicionalista de la península.

d) La élite brasileña descorrió el "velo" clel poder internacional. Es clecir que en este caso no existió la "doble percepción internacional" tan común en el resto de la región -un "centro legal" formalmente capacitado para imponer comportamientos (España) pero fácticamente incapacitado frente a otro "centro real" (Inglaterra).

Como variable relativamente dependiente de la ocupación española a la metrópoli destacaremos un hecho que, si bien reviste características económicas, nos interesará en sus aspectos políticos-militares. Como consecuencia del auge de la exportación azucarera del Brasil, Holanda, aprovechándose de los acontecimientos metropolitanos conquistará vastos territorios clel norcleste azucarero. Esta ocupación se prolongará durante 30 años (1624-1654).

Brasil deberá empujar fuera de su territorio al invasor, y si bien la retirada holandesa se produce luego de la expulsión de las tropas españolas de Portugal, el hecho mismo no dejó de constituir un aprendizaje para la élite brasileña. Ésta conocerá el peligro cle la desmembración territorial como consecuencia de la apetencia internacional que despiertan sus cuantiosos recursos.

En el año 1810 se desarrollarán en la metrópoli acontecimientos que se asemejarán a los pretéritos. Inglaterra impondráá concliciones a la corona portuguesa a cambio de la ayuda que ésta necesita para enfrentar la invasión napoleónica. En ese año se firmará un "tratado desigual" (por más que parta del supuesto de una formal igualdad) del cual saldrán beneficiadas las mercaderías inglesas -se obtienen tarifas de privilegio- y la flota de esa misma bandera.

Nuevamente Brasil jugará anticipadamente - sobre todo con respecto a la Argentina y México-. El expansivo poder biitánico consolidará su posición en el mercado brasileño, constituyéndose este país en un ejemplo de "tutelaje neocolonial" que, si bien es asumido ante la inevitabiliclad de los sucesos, no clejará cle buscar la ocasión de revertir esta situación de conclicionamiento externo.

Este Tratado de 1810 sufrirá sucesivas prórrogas (1827, 1843) hasta que finalmente en 1844 caducará. La razón de la denuncia brasileña debe atribuirse a las desventajas que en ese momento estaba ocasionando la "relación especial" con Inglaterra.

Nuevamente la élite brasileña tendrá ocasión de "probar sus dotes ejecutorias". Inglaterra reaccionará frente a la denuncia brasileña 
del Tratado y, tratando de afectar sustancialmente a la estructura económica del Brasil, amenazará con la represión del tráfico de esclavos.

El descubrimiento de oro en el nordeste va a provocar una nueva amenaza a su integridad territorial. Esta vez será Francia, quien intentará expandirse, buscando ampliar su colonia guayanesa, $y$ se interesará por las perspectivas que abre el nuevo mineral a la vez que reclamaba la libre navegación clel Amazonas (haciendo valer derechos originados en la Paz de Utrecht).

El intento francés, al igual que el protagonizado más tarde por los EE. UU. (quien buscaba una especie de internacionalización clel Amazonas) constituirán los últimos desafíos que deberá enfrentar el Brasil en el siglo xxx. En ambos casos, demás está decirlo, la diplomacia y las armas obtuvieron significativos triunfos."

La proclamación de la República y la clestacada influencia del Barón de Río Branco constituyen dos hechos significativos de la politica exterior brasileña.

La República se proclama sin que existan cortes o fracturas significativas. El agotamiento del sistema imperial llevaba a la necesidad de reformular naturalmente $y$ sin bruscas transiciones la estructura de poder. La política exterior gozará entonces de las ventajas del continuismo.

La gestión de Río Branco se desarrolla en un periodo signado por las modificaciones que se producen en la estructura de poder europea. Entre 1890 y 1900 Alemania sobrepasa a Inglaterra en materia de producción de acero y la desplaza de numerosos mercados. Los avances rusos y franceses preocupaban a Lonclres que se vería obligaclo a poner fin a su "espléndiclo aislamiento". Entre 1905 y 1914 se desarrollaron cinco grandes crisis: las franco-alemanas -de origen colonial-y las austro-rusas - de raíz balcánica.

Paralelamente a estos sucesos, en el continente americano se producian alteraciones en las relaciones de poder locales. Los EE. UU. acceden al status de potencia a fines del siglo pasado. La guerra de Cuba y la actitud de los EE. UU. respecto de evitar la participación europea en la región, constituyen algunos de los indicadores del protagonismo estadouniclense.

Río Branco deberá consolidar el territorio y el prestigio brasileño a través de innumerables negociaciones (el problema limítrofe con la Guayana inglesa, la cuestión del Acre, el Tratado de 1909 con Perú, los acuerdos limítrofes con Ecuador y Colombia, etc.).

Esta sofisticada madeja diplomática necesitaba, entre otras cosas, de respaldos externos. Los EE. UU. desempeñarán el papel que antaño le cupo a Inglaterra. Los antecedentes no faltaban. Descle

*Ver, Carlos J. Moneta, "La politica exterior del Brasil", en "De la Dependencia a la Liberación", La Bastilla, Bucnos Aires, 1973. 
1824 "el Brasil adherirá espontáneamente a los principios enunciaclos por la Doctrina Monroe, adoptándola, a partir de 1824, como uno de los puntos cardinales de su política exterior y procurando concluirsobre las bases de esta doctrina, una alianza ofensiva y defensiva con el Gran Estado del Norte". 5

Rio Branco siempre entrevió la necesidad de la cooperación con los EE. UU. a los fines de maximizar el poder intemacional del Brasil. Esta estrategia sin embargo no impidió el surgimiento de algunos conflictos como los desatados a principios del siglo como consecuencia de la actitud estadounidense de no reconocer los precios del café exigidos por el Brasil.

Mientras América Latina reclamaba cle los EE. UU. el fin del intervencionismo, Río Branco proponia la multilateralización de la Doctrina Monroe y su incorporación al Derecho Internacional Público Americano ${ }^{6}$. Bajo el seudónimo J. Penn, Río Branco publica en el Jornal de Comercio -bajo el título "Una vieja política de Amistad: Brasil, los EE. UU. y el Monroísmo"- un artículo en donde recomienda el mantenimiento de esta política que debe ser cultivada con el mismo empeño y ardor con que la cultivaron nuestros mayores". ${ }^{7}$

Las dos grandes guerras ay'udarán a terminar de definir no sólo la relación Brasil-EE. UU. sino también la totalidad de la política exterior brasileña. La alineación clel Brasil sin duda respondió a una apreciación realista del régimen internacional y del subsistema regional.

Será el diplomático Ruy Barbosa quien gralicará fríamente las alternativas en juego: "Europa está con América y América está con Europa"s. Mientras sus dos socios en el A. B. C. mantienen la neutralidad (más explicable en el caso irigoyenista), Brasil, consciente de la trascendencia de lo que estaba en juego, asume una actitud militante.

Los beneficios económicos y los réditos políticos no tarclarán en ilegar. Brasil participará clestacadamente en la construcción del "mapa" postbélico. $Y$ más aún, recibirá -aparentemente- el apoyo norteamericano en los primeros escarceos diplomáticos cle Versalles. Las aspiraciones brasileñas no terminaban allí. Aspiraba para sí a un puesto permanente en el Consejo de la Liga.

Esta actitud reflejará la condición de "amateur", el ufanismo de

sVer, Araujo Jorge, "Introdução as obras do barão do Rio Branco", Ministerio de Relaciones Exteriores, Río de Janciro, 1945.

oVer, Celso Lafex y Félix Peña, "Argentina y Brasil en el sistema de relaciones intermacionales", Nueva Visión, Buenos Aires, 1972.

7Ver, Carlos J. Moneta, "Brasil, una política", Documento de Trabajo interno del CEINAR, Buenos Aires, 1973.

sCitado por Carlos J. Moneta, ob. op. cit. 
quien ve en el mundo con una visión deformada -en tanto y cuanto no se valoraba en sus justos términos el poder, residual pero poder aún, de la aristocracia de potencias europeas. Brasil asignó a los EE. UU. un papjel protagónico de primer orden, aún mayor cle los que los mismos EE. UU. se autoasignaban. La caída de Wilson y el aislacionismo norteamericano restarán posibilidacles a la ambición brasileña. Como dato de interés recordemos la actitud argentina. Demostrando excesivo idlealismo -o también "amateurismo"- propuso reformas a la estructura cle la Liga. $Y$, al igual que Brasil, al no verse correspondida optará por retirarse.

A partir de la décacla del 20 el tema armamentista comienza a sex percibido como la clave del sistema de equilibrio establecido en el sur del continente. Brasil entiende que ha "empatado" al potencial argentino $y$, más aún, que está en condiciones de sobrepasarlo en un plazo no muy lejano.

El tema del equilibrio militar será, de ahora en más, recurrente. Sin embargo, a pesar de la importancia del tema, aún hoy permanece inexplorado cuando de suyo constituye uno de los obstáculos que más atenta contra cualquier intento de política cooperativa.

El "velo geopolítico" no sólo constituirá el "combustible de conflictos" sino que también sentará las bases de una falsa conciencia internacional. Aún hoy, numerosas cancillerias en vez de proceder en base a criterios políticos optan por el peligroso reduccionismo geopolítico. ${ }^{9}$

La alineación del Brasil junto a los aliados en la II Guerra Mundial resultará decisiva. De alli en más los EE. UU. lo considerarán el "aliado de confianza" y el interlocutor válido en la región.

El envío de tropas brasileñas al frente militar es algo más que un simbolismo. Brasil demostrará un comportamiento militante en favor de la causa aliada asumiendo a la vez los compromisos que entiende tener para con Occidente.

Desde la perspectiva exterior es útil relacionar el compromiso contraído en la II Guerra y los posteriores envios de tropas a Suez, el Congo y Santo Domingo. Las derivaciones que se desprenden de estos hechos son numerosas.10

Los dividendos de la militancia junto a los aliados no tardarán en evidenciarse. Los EE. UU. otorgaron amplio apoyo al programa desarrollista del Presidente Vargas, quien transformará al Estado

9Dentro de la literatura geopolitica destaquemos Ia obra del Tte. Coronel Mario Travassos, "Proyección Continental del Brasil", Círculo Militar, Biblioteca de Oficiales, Buenos Aires, 1941.

1oVer, Luigi Einaudi, Latin American Institutional Development: changing Mililary Perspectives in Peru and Brazil, Ministerio del Interior-Rand-Santa Mónica, 1972. 
en un agente racionalizador y promotor clel desarrollo. El apoyo se tracluce en el compromiso de financiar, a través de la Comisión Mixta, proyectos hasta un tope de 500 millones de dólares. ${ }^{11}$

La literatura "desenvolvimentista" ha divulgado extensamente los proyectos, metas y resultados del periodo varguista que, sin duda, estuvo signado por una voluntad política admirablemente orientada hacia la superación de los estrangulamientos de la estructura económica brasileña. Interesa también destacar al apoyo de la administración demócrata al primer proyecto desarrollista-reformista operado en América Latina. Más tarde, la administración republicana asumiendo la ya clásica política de ese partido para con la región abandonará a su suerte el proyecto varguista.

La denominada "política exterior independiente" desarrollada duxante las gestiones de los presidentes Quadros y Goulart presenta algunas singularidades. Entre ellas destacamos cierta ambivalencia entre lo que se declara y lo factual. Así el periodo en cuestión será rico en formulaciones y despierta generales expectativas que Iuego serán, en gran medida, defraudadas.

Los antecedentes del "independentismo" ya se manifestaron durante el gobierno de Kubitschek. Sin reanudar las relaciones diplomáticas con la URSS, en 1959 se firmará un importante acuerclo comercial ruso-brasileño. Otros ejemplos anticipadores: a) el frustrado intento de mediación entre los EE. UU. y Cuba; b) la apertura al Africa; c) la renta de azúcar a China Popular.

La política exterior fue entendicla como complemento del proyecto desarrollista y muy particularmente al servicio del Plan de Metas. La política "pombalista" percibía claramente los obstáculos con los que debía enfrentarse. De allí surgirá la propuesta que durante esos años se le presenta a los EE. UU.: la Operación Panamericana. En el fonclo se trataba cle un intento lúcido dirigido a captar capital blanclo y apoyo político externo en beneficio de toda la región.

Quadros y Goulart perfeccionarán la fórmula independentista en materia exterior. Aun reconociendo para la misna ciertos éxitos, y al solo efecto de encuadrarla dentro de un marco analítico, destacaremos algunos elementos que, sin duda, tuvieron presente los "decision makers" brasileños:

a) Quadros debió enfrentarse con un Parlamento en donde carecía de mayoría. Había llegado al gobierno sin estructura política propia y hallábase fuertemente acotado por la UDN.

b) Dadas las características del contexto político la "política exte11Ver, Helio Jaguaribe, "Desarrollo Político..., ob. op. cit. 
rior independiente" ¿no tendría la posibiliclad de ganar consenso y apoyo?

c) La actitud frente al caso Cuba ¿no era una forma de llamar la atención a los EE. UU. y a los grupos statuquistas?

d) La apertura al África ¿no es acaso un ejemplo de temor? El mismo Quadros darrá pie a la duda: "la explotación de los africanos por el capital europeo va en detrimento de la economía brasileña, puesto que permite que se estimule la competencia comercial sobre la base de trabajadores negros con bajos salarios". ${ }^{12}$

En última instancia, en el fondo se trató de llevar adelante una política exterior más abierta que a la vez sirviera a múltiples propósitos. Por un lado Brasil trató de sacar provecho de los cambios que se comenzaban a observar en el régimen internacional. Es más, hasta subyacía la intención de anticiparse a futuros acuerdos que no solamente los "grandes" realizarian sin consultar a sus "aliados" sino que también podían ocasionar perjuicios a los intereses brasileños. Por otro lado se trató de homogeneizar al frente interno, conseguir consenso (en el caso de Quadros) y paliar las expectativas reformistas y/o revolucionarias que durante el gobierno de Goulart alentaban algunos sectores.

Algunas conclusiones:

a) Brasil experimentó tempranamenté la experiencia del autogobierno. Paralelamente anotamos el surgimiento del "nativismo" -incipiente nacionalismo- un "ismo" que exalta la magnificencia del territorio, sus riquezas y la idealización de un futuro promisorio. En síntesís, una notable confianza en sí mismo $y$ en el futuro. Este tipo de exaltación nacionalista encontrará luego un perfecto complemento en el positivismo. La idéa de un "orden" - la estática comptiana- èl mecanismo del "progreso" - la dinámica- se integrarán a la tradición brasileña clando forma y' contenido al mesianismo del tercer milenio.

b) La política exaccionista de la corte lusitana alentará a la toma de conciencia respecto de los intereses propios. El "nosotros" y el "ellos" es percibido en términos conflictiros y hasta a veces traumáticos.

${ }^{12}$ Janio Quadros, "La Nueva Polftica Exterior de Brasil", reproducido del Foreign Affairs por Carlos Astiz, compilador, en "Latin American International Politics", University of Notre Dame Press, Notre Dame, Londres, 1969. 
Oarlos Pérez Llana / $₫$ Potencias intermedins o países mayores?

c) Los desafíos a la integridad territorial constituyen uno de los elementos constitutivos de la "memoria internacional" brasileña. Desde los intentos holandeses hasta los franceses, siempre la élite política percibió el valor del elemento territorio. En esto existe total consenso y continuidad. Nunca se planteó, ni siquiera como posibilidad, la cesión o pérdida de territorios - ni aun los marginales- a cambio de mantener los que se consideraban prioritarios.

d) Brasil, en pleno siglo xix, no turo reparos en enfrentarse con la potencia hegemónica de la época. Se trataba de poner fin a un tutelaje excesivamente oneroso, que si turo justificación en otras épocás, habia dejado de ser funcional.

e) Durante la gestión del Barón de Rio Branco, Brasil consolidará sus territorios. En esa circunstancia la diplomacia brasileña actuará a sabiendas de contar con el apoyo de los EE. UU.

f) La apertura a los EE. UU., iniciada durante la gestión branquista, se verá coronada con éxito como consecuencia del alineamiento brasileño en las dos grandes guerras. El equilibrio de poder local -restringido al Cono Sur- se verá alterado.

g) La nueva relación EE. UU.-Brasil constituye una palpable demostración de la sabiduría política brasileña en política exterior. El imperativo No 1 será el rechazo a cualquier tipo de "seguidismo". Si bien se juega con un actor preponclerante no necesariamente se debe renunciar a los objetivos de largo plazo, ni aún a los de corto plazo, considerados estratégicos.

h) La "política exterior independiente" lejos esturo de ser heterodoxa. Más bien se trató de responder a demandas del sistema político interno anticipánclose también a eventos que, hasta el momento, sólo eran manipulados por los "grandes"

INÉXIGO - ANTEGEDENTES HISTÓRICOS

La política exterior reservada y cautelosa, la actitud de desconfianza respecto del mundo exterior, la intransigencia en la defensa de principios que hacen a la autopreservación, v. g. la no intervención, y' en general la prudencia mexicana, ¿no se justifican en razón de sus trágicas experiencias histỏricas? 
México, la colonia más importante del Imperio Español, explotará el auge mineralífero más allá del 1800. El resto de las economías. latinoamericanas del tipo de enclave ya habían agotado sus reservas un siglo antes. De manera que mientras algunas regiones gozaban de la despreocupación metropolitana y otras de la perisferialidad geográfica y/o económica, México siguió ocupando un lugar destacado dentro de la perspectiva de la metrópoli.

El autogobierno tardará. Más aún, las posibilidades de surgimiento de una élite administrativa más o menos eficiente, que pudiera ejercer el dominio sobre los territorios y gozara de algún tipo de consenso dentro de los esquemas societales de la época, en ese primer periodo prácticamente resultó imposible.

Las movilizaciones de Hidalgo y Morelos produjeron verdaderos desajustes dentro de la estructura del poder tradicional. Lo que en otras regiones se logró sin sobresaltos - v. g. Brasil-o con efectos más o menos controlables - $v$. g. Argentina- asume en el país características mucho más conflictuales. Antagonismos inderimibles y prácticas violentas constituyeron el patrimonio -tal vez el más rico dentro de una perspectiva de cambio- del México ochocentista.

Resulta imposible atribuir posibilidades operativas a un proyecto nacional que imaginara para la sociedad mexicana, en aquellos años, un modelo del país deseado dentro de un contexto de mediana racionalidad política.

Durante el siglo xxx México perderá gran parte de su territorio. No podrá jugax (como lo hicieron otros países de la región) a contrabalancear sus relaciones exteriores a través de terceros. A partir del gobierno de Polk parecería que se hubiera alcanzado un modus vivendi entre Io EE. UU. y Gran Bretaña, en virtud del cual esta última aceptaba la supremacía estadounidense en América Central y Caribe.

Los privilegios de ciudadanos europeos que se vieron afectadios y/o envueltos en la intrincada vida política mexicana, jugaron también un papel negativo. So pretexto de deudas impagas, México resultará invadido en la década del 60 por potencias europeas.

Nuevamente factores exógenos influirán en la vida política mexicana. Terminada la Guerra de Secesión, los EE. UU. volverán a ocupar el vacio que circunstancialmente aprovechara Francia. De allí en más el tema de las "xelaciones especiales" con el poderoso recino constituirán el motivo de preocupación sustancial de cualquier gobierno mexicano.

Sin entrar a considerar los aspectos internos del."porfiriato", se puede afirmar con cierto asiclero que, tras la apertura al capital extranjero, subyacía una intencionalidad defensiva que entreveía el 
progreso -en la perspectiva positivista- como la única vía al alcance de México preventiva de futuras intromisiones externas.

Porfirio Díaz desempeñará, en este sentido, un rol bastante semejante - con todas las limitaciones que conlleva la comparación- al de Roca en la Axgentina a quien también le preocupará la ocupación efectiva del territorio nacional. La comparación puede enriquecerse aún más. Dos personalidades que se asemejan en su caracterología y sus propuestas, y son hijos del mismo "tempo".

Los desafíos a los que deberán responder también se asemejarán en algunos aspectos, y si bien Roca emprendió una política armamentista, ésta se explica en el contexto de la región. Además, la Argentina estaba en capacidad de responder militarmente a sus eventuales agresores. Porfirio Díaz jamás podría haber optado por idéntica política militar. Su fortaleza radicaba, precisamente, en la no posesión de fuerzas disuasorias.

Si alguna duda podía abrigarse respecto de las supremacías en la región del Caribe y América Central, quedarán despejadas en 1901. El Tratado Hay-Pauncefete constituyó la afirmación definitiva de la presencia norteamericana en la región, con el reconocimiento expreso de Gran Bretaña. A quien en México le tocara en suerte formular la política exterior debía, de allí en más, conocer las limitaciones y los parámetros que acotaban al espacio político regional.

El temor a nuevas amputaciones de territorio, y a los reclamos por bienes y/o derechos, está presente durante el periodo revolucionario. La élite política clebía cuidar simultáneamente dos frentes políticos interactuantes. En cualquier momento, bajo la excusa de poner a resguardo personas y bienes, se podía producir una nueva intervención que hubiera puesto en juego la propia experiencia revolucionaria.

A pesar de haber respetado las "líneas de borde", en 1914 México padecerá de una nueva invasión, esta rez Veracruz. Este atropello a la soberanía y a la integridad abrirá las viejas cicatrices de "la memoria política" mexicana. También aquí se originará un curioso sentimiento -curioso por lo atípico- hacia los países que interpusieron sus servicios al tratai de mediar entre México y los EE. UU. en la Conferencia de Niágara Falls (Argentina, Brasil y Chile). Fue objetado el intento de imponex un gobierno provisional.

México aprendió una dura experiencia. En primer lugar, no debía especular con la neutralidad de su vecino. En segundo lugar, se sintió incomprendido por Latinoamérica, quien no sólo no apoyó su causa sino que además intervenía en asuntos exclusivamente intexnos. ¿No constituirán estos hechos un antecedente explicatorio de la relativa despreocupación y/o aislamiento ulterior de México respecto de la región? 
Asegurada su victoria, la élite revolucionaria concentrará sus esfuerzos en la búsqueda de un modus vivendi con los EE. UU. Indudablemente se habia aprendido la lección de la historia.

La política exterior de la Revolución fue puesta al servicio de los objetivos centrales del programa revolucionario: Reforma Agraria y reversión al Estado de los recursos naturales.

Muchas de las expectativas nacionalistas y revolucionarias debieron ser sacrificadas en aras del modus vivendi. Los principios acordados en los Pactos de Bucarelli serán la muestra de una real-politik, tal vez excesivamente realista. De acuerdo a lo pactado, México se comprometía a no aplicar las disposiciones del artículo 27 de la Constitución (en donde se consagraba el dominio del Estado sobre los recursos naturales) a los bienes de ciudadanos norteamericanos. Igual selectiviclad fue aplicada respecto de las tierras. Mientras que la ley establecía la indemnización en bonos, los propietarios norteamericanos de tierras serian compensados en efectivo.

El idealismo revolucionario tarclará años en recuperarse. En 1925 Calles promulgará una ley reglamentaria en materia petrolífera en donde nuevamente México cuestionaba los presuntos derechos absolutos de las empresas sobre el subsuelo. Las empresas afectadas reaccionarán negándose a cumplir las disposiciones de la ley. El gobierno. norteamericano tomará cartas en el asunto, llegándose a una solución intermedia, que no satisfizo plenamente a ninguna de las dos partes, a través del Acuerdo Calles-Morrow firmado a fines de 1927.

El principismo había sufrido un nuevo golpe. Recién con la llegada al poder del general Cárdenas volverá a manifestarse arrogante. Habrá algunas excepciones. Así por ejemplo, en 1927 se reunía en Bruselas el "Congreso de los Pueblos Oprimidos" al cual Mréxico contribuyó con ayuda financiera.

Durante la gestión de Calles, las Fuerzas Armadas perderán gran parte de su poder. La formación del Partido Nacional Revolucionario constituyé un fuerte golpe para los caudillos militares.

Entre 1938 y 1941 los gastos de la defensa mexicana sólo eran superadosi por Brasil y la Argentina. En la década del 40 también Chile había șóbrepasado el gasto militar mexicano y en la del 50 Venezuela hará lo propio ${ }^{13}$. En 1970 la incidencia del gasto de la defensa por habitante alcanzaba la cifra de 3,98 dólares ocupando el puesto No 11, muy por debajo de la República Dominicana, Chile, Paraguay y Venezuela, con cifras similares a Ecuador y Bolivia. ${ }^{1 *}$

En la década cle los 60, si bien las cifras de los gastos de la defensa

18Ver, Horacio V́eneroni, "Estados Unidos y' las Fuerzas Armadas Latinoamericanas", Periferia, Buenos Aires, 1973.

14Horacio Veneroni, ob. op. cit. 
se mantienen bajas, se observa la cluplicación del porcentaje que esos gastos ocasionan al presupuesto nacional. En 1960 el porcentaje alcanzó el 6,7 \% elevánclose a $11 \%$ en 1965, todavía lejos de los niveles del Brasil (23\%), Colombia y la República Dominicana (24\%) y la Argentina y Ecuador ( $16 \%$ y $13,5 \%$ respectivamente)..$^{15}$

La asistencia militar extranjera es demostrativa del dimensionamiento militar y del rol que las fuerzas armaclas desempeñan en la sociedacl mexicana. Igualmente clemostrativo es el indicador compras militares. En 1972 las donaciones del programa PAM apenas llegaron a 0,2 dólares mientras que el total del rubro donaciones y compras para ese año alcanzaba a 1,6 millones de dólares contra 55,8 del Brasil y 14,3 de Guatemala. ${ }^{16}$

Estos datos revelan, entre otras cosas, la persistencia de la racionalidad militar decimonónica. ¿Qué sentido tiene una fuerza militar si ni siquiera podrá jugar como disuasora? Además, el rango que ocupan en el país los objetivos militares explica el mayor alejamiento de México y su relativa independencia respecto del aparato de seguridad regional.

Cárdenas gozará de circunstancias internas y' externas muy favorables. La fortaleza del sistema de alianzas internas (durante su gestión se reorganiza nuevamente el Particlo oficial) y la "política de buena vecindad" (que hacía descartable cualquier tipo de intervención) despejaban los obstáculos tradicionalmente reductores del dinamismo revolucionario.

La permisibilidad del contexto político interno y externo harán viable una política nacionalista -en el orclen internacional- y redistribucionista en el orden interno. El 18 de marzo de 1938 Cárdenas expropiaba la industria petrolera.

Las derivaciones de la nacionalización esta vez fueron más benignas. El apoyo interno, y los temores a un golpe pro-fascista ay'udaron a despejar las expectativas intervencionistas ${ }^{17}$. Cárdenas cerrará su gestión gubernativa habiendo alcanzaclo algunas de las viejas metas revolucionarias: mayor nacionalización del sistema de decisiones económicas y recuperación de los recursos naturales. Los pasados traumas habían siclo superados.

Destacamos también del período revolucionario algunos gestos internacionales coherentes con lá política de autopreservación mexicana. En 1931 aclherirá a la Sociedad de las Naciones haciendo la reserva respecto de la Incorporación de la Doctrina Monroe al artículo 21 del Pacto. En las Conferencias Panamericanas de Mon-

15 Idem ant.

16 Idem ant.

17Lorenzo Meyer, "Cambio político y dependencia", en Foro Internacional, octubre-diciembre, 1972. 
tevideo (1933) y Buenos Aires (1936), la delegación mexicana sostendrá firmemente las tesis anti-intervencionistas. Anteriormente, en 1924, se habían establecido relaciones diplomáticas con la URSS.

A partir de 1941 se inicia la etapa institucionalista. El poder político se había impuesto definitivamente sobre los otros poderes, el régimen gozaba de legitimidad y consenso, y se habían normalizado las relaciones con el mundo exterior.

El inicio de la etapa de "desarrollo hacia dentro" traexá aparejado el tema de la inversión extranjera. Si bien en la primera etapa el esfuerzo recayó sobre el capital nacional, a partir de la década de los 50 el comportamiento de la inversión extranjera se transformará en decisivo. Entre 1950 y 1960 ésta trepará de 560 millones de dólares a 1.100 millones de dólares.

Existían sin embargo ciertas restricciones jurídicas. El inversor extranjero, según lo establece la Gláusula Calvo, se compromete a someterse -en todo momento- a los Tribunales mexicanos ante la eventualidad de controversias que se suscitaren con motivo de nacionalizaciones, expropiaciones, etc. De manera que el inversionista extranjero debia renunciar expresamente a la protección diplomática de su propio Estado. Desde el punto de vista del Derecho Internacional no existe opinión unánime. Es más, constituye éste un tema poco explorado, a pesar de tener connotaciones tan profundas como vigentes. ${ }^{18}$

Descle nuestro ángulo interesan destacarse algunos aspectos. La aplicación de la Cláusula Calvo constituye uno de los primeros intentos regionales serios dirigido a fijar reglas de juego al capital extranjero. Cuando Calvo pergeña su doctrina, buscaba la defensa jurídica del principio que establece la ilegalidad de la intervención armada realizada so pretexto clel cobro de deudas, principio por otra parte aceptado en el Viejo Munclo y que luego retomaría la Doctrina Drago.

Para un país como México, que había padeciclo mutilaciones territoriales, agresiones y presiones, la Cláusula Calyo no dejaba de ser un instrumento totalmente funcional a los esquemas de autopreservación. Sin entrar a discutir Ios aciertos factuales de la Cláusula Calvo, lo cierto es que también ejemplifica una de las constantes de la política exterior mexicana: el juridicismo.

Este juridicismo se refleja en numerosas facetas de la política exterior mexicana. Sin duda, algunas veces éste resultó funcional, v.g. en el caso Cuba. En otras, el juridicismo devino en obstáculo,

isSobre el tema, ver, Juan C. Puig, "Renuncia individual a la protección diplomática. El problema de 'la legalidad internacional", en Rerista de Derecho Internacional y Ciencias Diplómaticas, Universidad Nacional de Rosario, 1969, Ne $35 / 36$. 
v. g. la aplicación de la Doctrina Estracla. Efectuando un balance, lo cierto es que el reduccionismo jurídico y el apego a las formas puede constituirse en un factor simplificador, en el sentido que el mismo puede llegar a transformarse en obstáculo de la imaginación y la audacia, $\tan$ necesarias en el fluido y competitivo régimen internacional contemporáneo. Coherentemente con este tipo de pensamiento, siempre ha habiclo en la Corte Internacional de Justicia un jurista mexicano.

Deliberadamente México "devaluó" su imagen internacional. A pesar de ser uno de los "grandes" de la región (en función de los indicadores tradicionales de estratificación) la élite política optó por la vía aislacionista. La experiencia - con toda su carga traumática- operó como elemento moderador y hasta a reces inhibidor de todo tipo de iniciativa. La prudencia y el deseo de no verse envuelto en ningún tipo de conflicto explican la marcada ausencia mexicana en el Consejo de Seguridad de las Naciones Unidas.

Esta actitud respecto del Consejo no se corresponde con el valor -casi simbólico- que México le asigna al organismo internacional. Al revés de la casi mayoría de los países latinoamericanos - la Argentina europeísta y decimonónica renegó durante mucho tiempo del panamericanismo- México siempre prefirió el marco universalista de la Asamblea.

En el foro internacional defenclerá el principio de la participación universal (sólo registra una abstención: la España de Franco) colocándose junto a la URSS cuando se trataron las aclmisiones de Rumania, Albania, Hungría y Bulgaria en 1955. Respecto de la admisión de China Popular; el voto mexicano generalmente se alineó junto a los EE. UU.

La política de aislamiento explica también las casi inexistentes relaciones con los paíes socialistas. Esto, que podría ser justificable para los otros países de la región -en función de razonamientos ideológicos- resulta un tanto extraño en un régimen que encuentra sus fundamentos en una práctica revolucionaria muy concreta. Esta singulariclad podría explicarse en función del temor tradicional a tocio tipo de intervención.

Durante la gestión del presidente López Mateos se modificarán las relaciones con los países socialistas (los sectores patronales reaccionarán adversamente). Por aquellos años México venía sufriendo las consecuencias del estancamiento de sus exportaciones de manera que la apertura era justificable desde todo punto de vista. En 1963 el presidente López Mateos visitará algunos países del este -Yugoslavia y Polonia- enviándose también misiones comerciales a la URSS, Checoslovaquia y China Popular. Pero a pesar de los incrementos habidos en el intercambio comercial, las relaciones con los 
países socialistas seguirán ocupando un lugar secundario en la estructura del comercio exterior mexicano. La Argentina y el Brasil mantendrán, en este sentido, una ventaja apreciable respecto de México tanto en el ítem intercambio como en la obtención de créditos.

\section{A.LGUNAS CONCLUSIONES}

a) La pérdida de territorios y las innumerables intervenciones extranjeras explican el temor que tradicionalmente ha manifestado México para con el mundo exterior como asimismo la actitud aislacionista y excesivamente prudente de su política exterior.

b) El realismo político y la búsqueda de un modus vivendi aceptable moderan la Revolución Mexicana (en materia externa) debiendo realizarse concesiones en materia de tierras y de expropiación de los recursos naturales.

c) Las Fuerzas Armadas mexicanas pierden el poder que durante un tiempo ejercieran en la vida política. Así Miéxico se verá exento de las perspectivas militares en materia internacional.

d) La defensa de la localidad, la exaltación de la justicia internacional y las necesidades de defensa dan origen al juridicismo internacionalista mexicano.

e) México ha preferido desenvolverse dentro de las Naciones Unidas pero ha evitado asumir responsabiliclades en el Consejo de Seguridad.

f) Las relaciones con los países socialistas, desde el establecimiento de las relaciones diplomáticas con la URSS en 1924, observan un comportamiento errático.

Durante la gestión del presidente López Mateos se hicieron es. fuerzos dirigidos a abrir los mercados del este a las exportaciones mexicanas. 
ARGENTINA - ANTEGEDENTES HISTÓRICOS

El clebate en torno de la política exterior a seguir respecto de las relaciones con la metrópoli española, dividió a la Primera. Junta de Gobierno en dos fracciones irreconciliables.

El proyecto morenista - de ideas próximas al jacobinismo- propugnaba la creación de un Estado centralizado, promotor y moclerador de los intereses societales en pugna. A ese estado le asignaba básicamente una tarea - en tanto y en cuanto él encarnaba a la sociedad civil-, la de "infiltrar" la socieclad -el Estaclo debía estar presente en todos los órdenes $y$ en todo momento- y la de asegurarse para sí el área geográfica en donde le correspondía ejercer su poder de imperium.

El proyecto contrario, circunstancialmente liderado por Saavedra, se caracterizaba por tener un "tempo" más lento y una prudencia que llegaba hasta confundirse con inmovilismo.

Moreno encarnaba los presupuestos expansivos. No se conformaba con la sola supeditación del territorio adyacente al puerto de Buenos Aires. Entendía que el Estado se justificaba ampliando su esfera de influencia y promoriendo el clinamismo social. Lejos estaba del morenismo la perspectiva de un Estaclo "infiltrado" por los grupos hegemónicos de la época (comerciantes y propietarios de la civita). En el ethos expansivo de Moreno confluirán las ideas del liberalismo radical y el proyecto exterior virreinal. ${ }^{19}$

Objetivamente, las relaciones de fuerzas internas operantes estaban en favor del proyecto conservador y protector del statu-quo. Exagerando y forzando los marcos de referencia resumiríamos este pensamiento de la siguiente forma: el mapa europeo luego cle la caída del poder napoleónico, tornaríase legitimista y conservador. Las potencias continentales resurgirían con sus plenipotencias intactas. Inglaterra no se jugaría por estas tierras. América Latina no estaba en capacidad de plantearse una política común en materia de clefensa. Conclusión: La prudencia aconseja "hacer buena letra"; no forzar las situaciones; prolongar el impasse juridico-político (la clenominada máscara de Fernando) y básicamente, en lo interno, jugar al equilibrio entre los intereses hegemónicos.

Esta será la primera de una larga serie de erradas percepciones del régimen internacional y de las condiciones de permisibiliclacl que el mismo nos ofrecía.

19Ver, Mariano Moreno, "Plan Revolucionario de Operaciones", Plus Ultra, Buenos Aires, 1967. 
En el afán de preservar los intereses de sector, la élite política no tratará de ampliar su espacio geográfico. De querer hacerlo hubieran necesitado -entre otras cosas- tener una noción más precisa de las relaciones de poder internacional o, lo que es lo mismo, conocer los límites exactos de "las líneas de borde" imperantes en el régimen internacional.

El triunfo de la fracción saavedrista constituye el epílogo del primer enfrentamien to entre proyectos políticos adversos. En gran medida se trató también de dos visiones disímiles del mundo y del papel que en él podían desempeñar las Provincias Unidas del Río de la Plata. A pesar de las características disímiles, ambos proyectos presentaban algunos puntos en común. El morenista jugaba más explicitamente a Inglaterra. Esto debe entenderse en su justo sentido. La apreciación era realista: frente al enemigo principal -España- era lícita y necesaria la alianza con Inglaterra. El proyecto saavedrista, llevado por la fuerza de los hechos devino, al tiempo, en una pertenencia directa al poder económico inglés.

El segundo enfrentamiento entre proyectos, en donde también se jugarán opciones extemas decisivas, tendrá características más difusas. Un grupo explicitará su proyecto y operara sobre la realidad: el rivadaviano. El otro grupo no tiene cabeza dirigente, sus propuestas son más implícitas que explícitas, careciendo de elementos políticos aglutinantes. Tal vez el arquetipo lo constituya San Martín, quien, contrariando el "provincialismo" de la época, tiene in mente una concepción estratégica que superará el marco de lo nacional.

Como suele ocurrir, triunfará quien posea mayores dosis de racionalidad política y de coherencia, ambas apoyadas, claro está, por las fuerzas societales hegemónicas.

Rivadavia fue un "eficientista" de la época. Así, abrió el mercado, desprotegiendo a la casi inexistente estructura económica nacional. En materia externa caracterizará su gestión la "displicencia" territorial. El grupo entendió que no tenía sentido entrar en una costosa política de preservación del territorio y mucho menos expandirse. Para ellos más valía asegurarse al poder en una porción del territorio -económicamente el más importante- que arriesgar la existencia misma de su régimen. Nacerá aquí una de las constantes más perniciosas de la política exterior argentina: el debate interno y los intereses de sector se convierten en los obstáculos inhibidores de la conducta exterior.

La vigencia del grupo y de las ideas preservacionistas explican el rechazo que Buenos Aires efectuará al pedido que San MTartín formulara descle el Pacífico que consistía en tropas y monetario. El 
expansionismo morenista y la visión estratégica de San Martín no pueden encontrar eco en un país envuelto en luchas internas.

La "autocracia esclarecida" que inaugura el gobierno de Don Juan Manuel de Rosas tiene por cometido básico la consolidación del Estado nacional. El país acababa de salir de la anarquía, era entonces necesario vertebrar $y$ ' concentrar el poder disperso. De manera que la política exterior debía estar al servicio cle esa magna tarea. El juicio crítico del historiador deberá ponderar la situación interna y ver hasta qué punto la política exterior resultó o no funcional al modelo.

El inconveniente con que tropieza el observador imparcial de este período radica en que el objeto del análisis carga con una fuerte dosis de elementos emocionales. Hasta el presente, esto cons. tituye tema de debate nacional. Cual el hombre de la caverna de Platón, el de hoy se debate en torno a sombras de un pasado ya remoto.

Un índice de la trascendencia que se le suele atribuir a la política exterior rosista lo obtenemos de la autorizada opinión de J. Carlos Puig quien, al enumerar "las deformaciones ópticas" que aquejarían a los estudiosos de la política exterior argentina, cita (aclemás de las deformaciones "idealistas-literarias" y "juridicistas") precisamente a la "revisionista". Ésta consistiría "en suponer que la Argentina ha tenido dos políticas exteriores; la del entreguismo y la de afirmación del ser nacional, correspondiendo naturalmente esta última al período rosista (con concesiones al irigoyenismo)"..20

Rosas, federal y a la vez representante de los intereses de la Provincia de Buenos Aires, debe practicar una política de "equilibrio restringido" (entre los intereses portuarios y los del Litoral), restringido en el sentido que tendrá en cuenta los intereses de dos de las regiones geográficas, en definitiva "la pampa húmeda". Así se explica la diligencia con que procede frente a las intervenciones europeas (inglesa y francesa), puesto que afecta a esos intereses, y la relativa lentitud que demostrara en otros casos, como, por ejemplo, Tarija.

Por esos años el régimen internacional observaba cambios profundos que repercutirían en el Río de la Plata. En 1S22, en el Congreso de Verona, Inglaterra manifestaba su clesacuerdo con el restauracionismo absolutista. Todavía la isla no había abolido el proteccionismo agrícola pero de todos modos, el interés comercial inglés no podía lejar libraclo a su propia suerte a los mercados latinoamericanos. [.us sectores de la burguesía comercial imponen por esos años a uno de los suyos al frente del estratégico Foreign

20Juan C. Puig, "Tendencias de la Politica Evterior Argentina" en "Lineamientos de un nuevo Proyecto Nacional", Buenos Aires, 1970. 
Office, George Ganning. Durante su gestión Inglaterra abandonará la política de solidaridad europea sustentada por su antecesor en el cargo: Castlereagh.

También se habían introduciclo nuevos factores dentro de la diplomacia regional. La Doctrina Monroe; el establecimiento cle relaciones diplomáticas entre los EE. UU. y algunos países de la región (Provincias Unidas del Río de la Plata, México, Colombia y Chile) $y$ los intentos de unidad latinoamericana, son ejemplos elocuentes de la nueva impronta.

En medio cle los nuevos signos, la diplomacia rosista debió equilibrar permanentemente. El sistema de poder interno, todavía no cohesionado, y los problemas externos, constituyeron desafíos que, por su magnitud, no estaban en condiciones de ser superados por un régimen que ya padecía el desgaste del largo periodo de ejercicio del poder.

Rosas constituye el punto medio entre las dos opciones de la época: el "provincianismo" de un Francia que entreveía la solución para el Paraguay en el aislamiento $y$ las propuestas de apertura total de los unitarios. Fue también una etapa de transición entre dos visiones del mundo, manifiestamente antitéticas, referidas al rol de la Argentina en ese munclo $y^{\prime}$ en la región.

Durante el gobierno de Rosas, un reducido grupo de jóvenes intelectuales comenzaba a pensar en el país. Los temas externos constituían uno de los aspectos centrales del programa que comenzaba a gestarse. Los estudios de la realidad adyacente, los que se referian al futuro y a los mecanismos operativos, convergían en el tratamiento del mundo circundante. El "por qué" y el "para qué" clel país necesitaban de un marco de referencia.

La ley de expansión de la humanidad, en la cual creía ciegamente el numen de la generación, J. B. Alberdi, consistía en la afirmación "del mejoramiento indefinido de la especie humana, por la mezcla de razas, por la comunicación de ideas, por la nivelación de culturas". ${ }^{21}$

Según este pensamiento, en un tiempo se pudo justificar la presencia de España en la medida que ella encarnaba el proceso civilizatorio. Para Alberdi, la clave del progreso de los EE. UU. residía justamente en "el ajuste comedido a aquella ley general"22. La Argentina, por no "ajustarse", permanecía fuera del proceso civilizatorio.

La clave del esquema de Alberdi consiste "en la natural ecuación favorable de los intereses europeos con los nuestros. Esta es la idea fuerza que determinará nuestra política internacional y económica"³.

"Citado por Héctor Ciapucio en "Lineamientos de...", ob. ant. cit. 22Idem. ant.

ridem ant. 
Decía Alberdi: "mientras mantenemos nuestros ricos territorios vacios e inútiles, Europa sufre plétora de población".

Sin cluda no existió racionalidad política equiparable en ninguno de los proyectos de la época y' que además, fuera asumida - como lo fue ésta- por sucesivos gobiernos. En estas ideas alberclianas se puede encontrar la fundamentación de la política exterior argentina.

La racionaliclad de la dependencia y cle la inserción periférica encuentran en Alberdi un militante defensor. Usará el método comparativo; en este caso cotejará las alternativas que se le presentaban a los EE. UU. y a la Argentina. Forzando los razonamientos, Alberdi concluye demostrando la inviabilidad y las inconveniencias de una política aislacionista y proteccionista para la Argentina. Por el contrario, sostendrá que el país se halla en óptimas condiciones como para sobresalir como pals periférico.

LAS TENDENCIAS DE LA POLÍTICA EXTERIOR ARGENTINA ${ }^{24}$

\section{a) Afiliación a la esfera de influencia británica}

El crecimiento del poderío de la burguesía industrial británica terminará con el proteccionismo agxícola en $1849^{25}$. Se inicia así la segunda etapa de la Revolución Industrial destacándose, también en esos años, el desarrollo acelerado de las técnicas del transporte.

Gran Bretaña saldrá beneficiada y fortalecida de este proceso. El Congreso de la Paz reunido en París en 1856 significó para la isla un gran triunfo diplomático al obtener la neutralización clel Max Negro y la desaparición de la flota rusa. En Paris, la flota inglesa conseguirá la hegemonía naval en base a la cual se convertiría en el árbitro supremo del intrincado mapa diplomático europeo.

Primera potencia económica, primera potencia militax, esto no dejaba de cleslumbrar a cualquiera. La Argentina no escapó al mecanismo de los efectos demostrativos. Como bien dice Puig, "si existe libre cambio, si se descarta la posibilidad de promover una industria autóctona, si la distribución de las tierras lleva a su concentración en pocas manos, las circunstancias de hecho empujan naturalmente a que el pais entre en la esfera de influencia británica"..6

24Esta tipologia pertenece a Juan C. Puig quien la esboza en "Tendencias de la Política Exterior Argentina", ob. ant. cit. Agradecidos, reconocemos su total paternidad.

25Ver, Celso Furtado, "La economía latinoamericana desde la Conquista Ibćrica hasta la Revolución Cubana", Edit. Universitaria, Santiago de Chile, 1969.

20En "Tendencias de la política exterior argentina...", ob. op. cit. 
b) Oposición a los EE. UU.

El enfrentamiento argentino-estadounidense se profundiza a medida que ambos consolidan sus propios frentes. Mientras los problemas internos relegaron a un segundo plano a los temas internacionales, ambos paises se ignoraron. Mas, cuando lograron articular sus propios sistemas de poder y comenzaron a avizorar el horizonte internacional que se les abría, sucederá la política de mutuo hostigamiento.

Las causales de los conflictos eran diversas. Ambos paises ostentaban peligrosas similitudes, v.g. tierras ricas, cultiros, ambiciones de liderazgo, etc. Las posibilidades de complementación eran casi nulas. El proteccionismo impuesto a los EE. UU. después de la Guerra cle Secesión y el fomento a la producción agrícola constituyeron, desde el vamos, obstáculos insalvables para el estrechamiento de las relaciones bilaterales. El impuesto aduanero sancionado por el Congreso Republicano en 1867 a la lana argentina constituyó, por largo tiempo, el factor de irritación para la diplomacia argentina. ${ }^{27}$

El intento norteamericano de promover una Unión Aduanera continental, y la convocatoria a la Conferencia de Washington en 1S89, constituirán los nuevos escenarios de los conflictos bilaterales.

La afiliación europea, más precisamente británica, de la Argentina debía necesariamente enfrentarse con el proyecto aduanero que, obviamente, en caso de prosperar hubiera aumentado la presencia comercial de los EE. UU. en Latinoamérica. Frente a esa posibilidad la Argentina debía oponerse. Muchas cosas estaban en juego. Las ansias de liderazgo argentino hubieran desaparecido y los intereses ingleses también saldrían perjudicados. La frase del representante argentino a la Conferencia "América para la humanidad" era una buena traducción del pensamiento implicito "Argentina y América con Europa".

Durante la segunda fase del panamericanismo (la primera fracasará en la misma reunión de Washington), la Argentina liderará la oposición a la política intervencionista. Luego repetirá el papel al oponerse tenazmente a Ios proyectos de institucionalización del mecanismo de consultas. ${ }^{28}$

27Harold F. Peterson, "La Argentina $\mathrm{g}$ ' los Estados Unidos", Eudeba, Buenos Aires, 1970.

28Ver, Alberto Conil Paz y Gustavo Ferrari, "Política Exterior Argentina", Círculo Militar, Buenos Aires, 1971. 


\section{c) Aislacionismo respecto de América Latina}

Mariano Moreno responderá a la propuesta federativa de Martínez de Rosas, diciendo: "¿Quién podría concordar las voluntades de los hombres que habitan en un continente donde las distancias se cuentan por miles de leguas? ¿Dónde se fijará el gran Congreso, y cómo proveería a las necesidacles uxgentes de pueblos de quienes no podría tener noticias sino clespués de tres meses?"29

Alberdi en su "Memoria sobre la conveniencia y objeto de un Congreso General Americano" (Santiago de Ghile, 1844) dirá: "Los actuales enemigos de la América están abrigados dentro de ella misma; son sus desiertos sin rutas... En América el vasto territorio es causa de desorden y atraso... El terreno es nuestra peste en América, como lo es en Europa su carencia..."

El razonamiento reduccionista, que encontraba en la vastedad de los territorios y en la dificultad de las comunicaciones los elementos que hacían imposible la unidad latinoamericana, dio forma $y$ senticlo a la política exterior aislacionista de la Argentina respecto de la región. Consecuente con estas ideas, el país estará ausente durante la etapa bolivariana de la integración.

A esta razón geográfica se le agrega una variable ya más voluntarista y que, tal vez, resulta decisiva para quien pretenda explicar la política exterior argentina. Para Alberdi, y para los ejecutores de su proyecto, el país debía ingresar a la civilización. Esto y decir que la región estaba excluicla de antemano era lo mismo. El modelo consistia en la implantación de la civilización europea en la Argentina. Al servicio de esta política había que sacrificar todo. La piedra angular clel sistema será entonces la importación de todo cuanto tuviera color y sabor europeo.

\section{d) Debilidad de la politica territorial}

La debilidad de la política argentina puesta de manifiesto en las cuestiones territoriales podría ser explicada, en un primer análisis, según la óptica de la escuela "xevisionista". Ésta sería un ejemplo de la política de "la entrega".

Sin embargo, si se pretende aranzar más allá de los blancos y los negros, debemos apelar al método interrogativo. ¿Hasta qué punto la "entrega" fue patrimonio exclusivo de los "malos" de la historia? Quienes ceclian o se despreocupaban clo hacían a sa-

29Citado por Juan C. Puig, en "Tendencias de...", ob. ant. cit. 
biendas del valor presente o futuro de los territorios en disputa? ¿Qué era percibido como prioritario para los decididores decimonónicos?

Respecto de la primera pregunta, y'a adelantamos nuestras dudas. Pensamos que la constante es más o menos común a los "buenos" y a los "malos" de nuestra historia. Respecto del valor que se le asignaba al elemento geográfico, digamos que era ínfimo. No importaba perder unos kilómetros cuando habían miles sin explotar. $Y$ en cuanto a lo que era prioritario, congruentemente con el pensamiento alberdiano, lo eran la paz y el orclen interno. A ambos, la Constitución y el gobierno debian protegerlos.

Estas cuatro tendencias mantuvieron su vigencia hasta bien entrado el siglo xix. La diplomacia argentina se aferró a ellas como si fueran inmutables los marcos de referencia que las justificaron.

La adhesión a la esfera de influencia británica persistió a pesar de haberse producido sustanciales modificaciones clentro del régimen internacional. El ascenso al poder del radicalismo se produjo sin que se introdujeran cambios en el esquema de inserción dependiente. Más aún, la neutralidad argentina fue en gran medida funcional a los intereses ingleses, en la medida en que éstos se aseguraban el aprovisionamiento a través de una bandera neutral. Respecto al tono de las relaciones bilaterales argentino-inglesas durante el gobierno radical, recordemos que durante la segunda presidencia de Yrrigoyen el gobierno argentino se hará eco de las conclusiones del Comité Balfour y' del Informe D'Abernon. Éstos reflejan la preocupación del capital inglés ante el cleslizamiento que sufren sus productos en el mercado argentino como consecuencia de la expansión estadounidense. Tocará a Yrigoyen poner fin a la convertibilidad del peso.

Sin embargo, a pesar cle la crisis mundial del 30, la Argentina no entreveía otra alternativa internacional. Hubo una supeditación ideológica a las condiciones internacionales pretéritas. La caída de la libra en 1931 y el Pacto de Ottarva debieron llamar a la reflexión, mas sin embargo sólo se atinó a reacomodar el esquema dependentista.

La Argentina, inerme e indefensa, firmará el Tratado Roca-Runciman a cambio de ser reconocida en el esquema imperial. En ese momento la Argentina "hipotecará" su poder de negociación. Quedarían fuera del alcance de nuestra diplomacia las posibilidades de un juego pendular. La dependencia ahora sería ineficiente.

La nueva política económica de Pinedo (en la década del 30) tratará de salvar la relación "especial" con Londres (aunque ya se percibía como irremediable su decadencia). La necesidad de mantener el comercio con Gran Bretaña continuará vigente en el pensamiento de la élite política. Sostenía una publicación especializada de la 
época: "Cualquier reclucción en" nuestras compras de ciertos países (Gran Bretaña) podría traer una contracción de nuestras ventas. Esto debe ser evitado a toda costa".30

Ya declinante, el sol inglés todavía "iluminará" por sobre la politica exterior argentina de la década del 40. Tras las tesis neutralistas existía el interés inglés. Nuevamente a Londres le interesará una bandera neutral. Además la City no se resignaba a percler su último aliado en América Latina. Aunque esto tiene que ver con otra guerra, más-sorda, la que vanamente libraba el decadente imperio con los EE. UU. Tan cierta es esta imagen que hasta hubo analistas que entrevieron una intervención inglesa en el movimiento militar que derrocara al gobierno del General Perón en 1955..$^{31}$

La oposición a los EE. UU. se haxá evidente en la clécada del 30. Por esa fecha la diplomacia de "prestigio" alcanza su apogeo. Las banderas clel no-intervencionismo y el no-colaboracionismo (durante la guerra) son levantadas por nuestra diplomacia militante.

La historia de las reuniones panamericanas a partir de la Reunión de Montevideo en 1933 (ya en la cle Santiago en 1923 se habían producido enfrentamientos) mostrará a una Argentina intransigente.

El país ambicionaba heredar la hegemonía inglesa y se consideraba naturalmente llamado a desempeñar el papel de líder. El Pacto antibélico negociado por el canciller argentino Saavedra Lamas y la "Guerra por la Paz" 32 entablacla entre los EE. UU. y' la Argentina respecto de la conducción de las tratativas de la paz del Chaco, constituyeron las horas más felices de la cliplomacia cuestionante.

La soledad argentina en la Reunión cle Rio cle 194.2 (se trató el tema de la ruptura con el eje) significará el fin cle "la política de personalidad". La Argentina quedará excluicla de la ley sobre Préstamos y Arriendos y del panamericanismo. Tampoco gozará de la confianza continental.

Ese aislamiento de la Argentina para con la región resultará la constante más perclurable. La despreocupación territorial prácticamente no operará en las últimas décadas (podría ser una excepción el Trataclo Antártico). La aclhesión a Gran Bretaña se agotará con el correr de los hechos y el enfrentamiento con los EE. UU. dejará de ser recurrente. En sintesis, toclas las tendencias fenecerán o se transformarán. Sólo el aislamiento continuará vigente.

Existen sin embargo algunos ejemplos que podrían ser esgrimidos

30Del suplemento Estadistico de la Revista Económica, citado por Javier Villanueva en, "La gran depresión y el desarrollo industrial argentino", trabajo inédito, Buenos Aires, 1972 .

31Entre otros, Arthur Whitaker, "La Argentina $y$ los Estados Unidos", Edit. Proceso, Buenos Aires, 1956.

s2De Conil Paz y Ferrari, ob. ant. cit. 
para afirmar lo contrario. Pero ellos no resisten a un análisis riguroso. El Pacto del A.B.C. ¿no fue acaso una buena fórmula de contención mutua entre los protagonistas del equilibrio zonal? La Conferencia Regional del Río de la Plata (Buenos Aires, 1941) tho fue acaso un intento de buscar soluciones inmediatas a los problemas económicos ocasionados por la guerra? Y anteriormente, la gestión de paz entre Bolivia y Paraguay ¿no fue sólo un ejemplo de diplomacia cle prestigio?

\section{Algunas conclusiones}

a) La derrota de los proyectos morenistas y sanmartinianos ocasionaxán a la Argentina dos graves daños en materia exterma: pérclida de territorios y de tiempo.

b) El proyecto alberdiano marcará Ia impronta exterior de los sucesivos gobiernos posteriores a la etapa de la Organización Nacional.

c) Las tendencias básicas de la política exterior argentina fueron: a) adhesión a la esfera británica; b) enfrentamiento con los EE. UU.; aislamiento respecto de la región; c) despreocupación territorial.

d) A pesar del tiempo transcurrido y de los cambios que se observaban en el mundo, la élite política argentina se aferró a estas tendencias de manera ciega y absoluta.

e) Hasta la segunda Guerra Mundial, Europa siguió siendo consiclerada como el "centro".

f) Como consecuencia del fin de la hegemonía inglesa, la Argentina volverá a la región, remisa y claudicante.

g) De tiempo en tiempo, como si los años no hubieran corrido, la diplomacia argentina "reflota" alguna de las viejas tenclencias, generalmente la de mirar hacia el Viejo Continente y la de aislarse respecto de la región. 
LA POLÍTICA EXTERIOR DE LA ARGENTINA

Quien pretenda comprender la actual política exterior argentina debe; entre otras cosas, tener presente algunos antecedentes históricos que resultan decisivos: la denominada Tercera Posición y los Acuerdos Económicos firmados durante la segunda presidencia del Greneral Perón. Deberá también conocer el pensamiento del líder justicialista referido a algunos temas de indudable trascendencia internacional: su concepción de la historia, su esquema cle integración, el tema de la calidad de vida, etc.

En lo que respecta a Ia Texcera Posición, habiamos sostenido en otros trabajos ${ }^{33}$ que el tercerismo podía ser definido desde dos perspectivas: a) Como postura internacional. b) Como una concepción doctrinaria que hace referencia a la naturaleza de los sistemas politicos y económicos.

El ejemplo típico de a) sería la política exterior gaullista. Decíamos: "un capitalismo nacional emergente si no puede negociar en términos justos con el capitalismo hegemónico y siempre que posea un mínimo potencial político-militar, puede aventurarse a cuestionar la. política de bloques desconociendo, en consecuencia, las áreas de influencia"34. Según se observa, el. planteo es exclusivamente internacional y no postula -ni siquiera implícitamente- ninguna concepción novedosa respecto de los sistemas. Sólo pretende constituirse, en un mundo bipolar, en un polo de atracción internacional. Para eso necesitará introducir en su tercerismo unas muy vagas propuestas. de democratización internacional.

La Tercera Posición como: alternativa doctrinaria, según la óptica de quienes la formulan, destácase como una nueva concepción de tipo' valorativo, diriamos una cosmovisión. Esta perspectiva pretende superar la lucha de clases, el individualismo liberal y el colectivismo. Se convierte entonces al Estado en una instancia moderadora. Él se justificará en tanto y en cuanto arbitre por sobre las fuerzas societảes debiendo estas últimas encuadrarse dentro de una "comunidad orga" nizada".

Ambas perspectivas diferirán sustancialmente en materia internacional. Se distinguen básicamente en el tipo de arquitectura poli-

${ }^{33}$ Carlos Pérez Llana, "América Latina y los paises no-alineados" en "La Politica de poder en América Latina", Pleamar, Buenos Aires, 1974.

s*Idem, ant. 
tica que desearían que se estableciese en el mundo. El tercerismo gaullista no cuestiona la estructura verticalista del régimen internacional. Se opone a los "abusos" y' respeta los "usos". Se opone también al sistema en la medida en que no participa, ha sido excluido. En consecuencia, cuando este tipo de tercerismo plantea una política horizontalista lo hace como táctica. Para acceder y ser reconocido por los administradores supremos de la bipolaridad no dejará de usar cualquier tipo de métodos (incluido el horizontal). En síntesis, la lógica opera de la siguiente forma: Existe una aristocracia cerrada dentro del régimen internacional, trato de acceder a ella $y / 0$ ser reconocido, no lo logro. ¿Qué hacer? Aumentar mi poder de negociación. Esto significa: 1) obtener poder de disuasión nuclear; 2) fortificar el Estado; 3) apoyo deciclido al capital nacional, y 4) buscar anudar cualquier tipo de alianzas.

Respecto del tercerismo doctrinario, ¿cuál es su "estructura ideal" del régimen internacional? Por definición la propuesta se fundamenta sobre una concepción solidarista del régimen internacional. Privilegiará entonces las relaciones horizontales. Cuestionará los "usos" y los "abusos" de la estructura verticalista. La visión estará próxima al universalismo. Tratará, al fin, de intexpretar y ajustarse a los "signos de los tiempos".

La Tercera Posición Justicialista puede ser identificada como más próxima a la formulación tercerista-doctrinaria. Esto no significa que, por razones de circunstancia, se excluyan definitivamente algunas prácticàs internacionales propias del tercerismo no doctrinario.

Así, por ejemplo, el tema del desarme se presenta, en el caso argentino, como un área no del todo definida. Recordemos además que lo político-militar internacional siempre constituyó un tema atractivo para el líder justicialista. Durante los anteriores gobiernos del Tte. General Perón, la política nuclear gozó de la preferencia y la atención del gobierno nacional. El estadio alcanzado por el país en este terreno se debe, en gran parte, a aquella preocupación verdaderamente anticipadora. Con estos antecedentes, ¿cuál es la interpretación que puede adelantarse respecto de la posición argentina en materia de desarme internacional?

A manera de hipótesis trataremos de respondernos. Como ya lo adelantáramos, en algunas circunstancias, el tercerismo justicialista no descarta las prácticas del tercerismo no-doctrinario. La problemática relacionada al desarme internacional ofrece un buen ejemplo de entrecruzamiento (recordemos también al lector que, en relaciones internacionales, los "tipos-ideales" son justamente "ideales").

A nuestro entender, el tercerismo justicialista no puede dejar de cuestionar - tal vez descle una perspectiva muy gaullista- lo que se 
ha dado en llamar "el congelamiento del poder mundial"35. El desarme, tal como se lo viene planteanclo hasta el momento, constituiría una de las herramientas claves clel "congelamiento". De manera que podemos arriesgar nuestra hipótesis: los fines implícitos y explícitos que subyacen tras las actuales propuestas de desarme internacional no coincidirian con el tercerismo justicialista.

Otros marcos de referencia se refieren al proceso de integración. La política exterior vigente relacionáda con la región, y más precisamente con el tema de la integración latinoamericana, reconoce como antecedentes destacados a los Acuerdos de Unión Económica que se establecieron con algunos países de la región en la década del 50.

El ejemplo más acabado de perfeccionamiento, dentro de estos Acuerdos, lo constituye el Tratado de Complementación Económica firmado con la República de Chile. De él dirá el General Perón: "En ese Tratado de Complementación Económica se perseguía inicialmente interesar a los países hermanos del continente en una acción económica común, de mutua defensa, como punto de partida para una integración ulterior de mayores alcances, con los siguientes objetivos:

- Crear, gracias a un mercado ampliado, sin fronteras, las condiciones más favorables para la utilización del progreso técnico y la expansión económica.

- Para evitar divisiones que pudieran ser utilizadas para explotarnos aisladamente.

- Para mejorar el nivel de vida cle nuestros doscientos millones de habitantes.

- Para dar a Latinoamérica, frente al dinamismo de los "grandes" $y$ ' el despertar de los continentes, el puesto que debe corresponderle en los asuntos mundiales.

- Para crear las bases de los futuros Estados Unidos de Sudamérica."

La claridad de los conceptos vertidos en el documento "La Hora de los Pueblos" nos eximen del análisis. Sólo destacaremos algunos que seguramente nos ayudarán a interpretar algunas de las actuales

35Ver J. A. de Araujo Castro, "El continente Americano dentro de la Problemática Mundial", Estudios Internacionales, Octubre-diciembre de 1972, No 20 (Publicación del Instituto de Estudios Internacionales de la Universidad de Chile). 
manifestaciones de la política exterior argentina, siempre referidas al tema regional:

En el citado Documento subyacen las siguientes ideas respecto de la Integración Latinoamericana:

a. Ventajas de escala que ofrece la integración.

b. Se evita el juego competitivo interno.

c. La integración como instrumento de los procesos de cambio.

d. Maximización del poder regional a través de la unidad.

e. Objetivo finalista: la unidad política.

Se destaca también en el pensamiento del Tte. Gral. Perón una visión muy particular del proceso histórico. Dirá en el documento "La Hora de los Pueblos": "La evolución nos llevará imperceptiblemente hacia la revolución y no habrá fuerza capaz de detenerla". La fuerza evolutiva de la revolución culminará en una especie de convergencia universal: el continentalismo. Actualmente nos enfrentaríamos, según este pensamiento, con "la hora de los regionalismos", de alli la necesidad - hija del "fatalismo evolutivo" - de integrarnos al más breve plazo: "El año 2000 nos encontrará unidos o dominados".

Tampoco escaparán a esta visión universalista los temas relaciomados a la civilización tecnológica. El inarmónico desarrollo de los elementos técnicos estaría destruyendo aceleradamente el equilibrio ecológico. En su Documento Ecuménico dirigido a las Naciones Unidas, entre otras apreciaciones, dirá Perón: "el ser humano ya no puede ser concebido independientemente del medio ambiente que él mismo ha creado".

ALGUNOS DE LOS GRANDES TEMAS DE LA ACTUAL POLÍTICA EXTERIOR

E1 25 de mayo de 1973, fecha del acceso al gobiemo del Frente Justicialista de Liberación, bien puede citarse como un corte en materia de política exterior.

El país había observado la ejecución de una política exterior en gran medida signada por los presupuestos ideológicos de la "guerra fría". Sin entrar a considerar críticamente la política del período 
66-73, que no es nuestro tema, tal vez resulte útil caracterizar algunos de sus rasgos en la medida que éstos ayuden a efectuar comparaciones.

Las relaciones con la Comuniclad Europea constituyeron el tema central cle la cliplomacia militar. Las negociaciones con el Viejo Continente eran el "termómetro" que reflejaba nuestra posición en el munclo.

América Latina ocupaba un lugar secunclario dentro cle la planificación de la política exterior: Se dudaba, incluso, respecto de las ventajas y de la viabilidad del proceso integrativo. La Argentina había retornado al viejo estilo aislacionista.

La supeditación a las rigideces ideológicas y la adhesión a esquemas verticalistas (por cierto supeditantes) explican la insipida actuación internacional clel país. El mapa internacional comenzaba y terminaba en "Occidente"; lo demás no existía. Es más, como los antiguos temían deĩ mundo todavía inexploraclo, la diplomacia argentina sentirá temor y complejos frente a un mundo que no llegaba a comprencler.

La falta de actualización y de aclaptación a las nuevas reglas de juego internacionales se tradujeron en el "gap-político". La Argentina deliberadamente ignoró las infinitas posibilidades que se le ofrecían a nivel internacional y prefirió autodevaluar su margen de maniobra.

El nuevo gobiemo justicialista recibirá entonces un balance de política exterior con "techo" internacional". Ese "techo" se constituía de todas aquellas alternativas que el gobierno anterior había optado por no usar, dado que no era su intención maximizar la autonomía.

Permítasenos tratar una breve cronología de la reciente conducta exterior argentina.

a. Desde los momentos previos al 25 de mayo de 1973 ya se podían observar algunas de las pautas de la política exterior justicialista. Los asuntos externos ocuparon un lugar trascendente dentro de la Plataforma Electoral del FREJULI (Frente Justicialista de Liberación). Allí se trasuntaban algunos de los grandes temas internacionales que preocupaban a la conducción frentista, v.g.: América Latina, Tercer Mundo, No-Alineados, Pluralismo ideológico, etc.

Las invitaciones que las autoridades electas formularan a algunos Jefes de Estado y a distinguidas personalidades políticas - como así también las omisiones - estaban dando un tono característico al tema internacional.

b. Apenas instaladas las nuevas autoriclades (con la presencia de 
numerosas y jerarquizadas delegaciones que prácticamente otorgaron una especie de consenso implícito al nuevo gobierno) fueron restablecidas o se establecieron relaciones diplomáticas con numerosos países, entre otros: Cuba, República Democrática Alemana, Corea del Norte, etc.

c. En la primera sesión de la "Comisión Especial para estudiar el Sistema Interamericano y proponer medidas para su reestructuración", la delegación argentina propuso una reforma sustancial de la estructura del sistema. Entre otras formulaciones se destaca la autocrítica que formula la Argentina frente a las naciones hermanas: " IImpedimos la perspectiva de la unidad política, de un desarrollo común y autónomo, propiciamos el aislamiento y la autarquía como si por nuestros propios medios hubiéramos podido lograr superar los obstáculos que obstruian el camino hacia la autonomia!"

d. En la X Conferencia de Ejércitos Latinoamericanos (Caracas, 3-7 diciembre de 1973) la delegación argentina anunciará la interpretación que sustenta el gobierno nacional respecto de la seguridad. En uno de los párrafos, el Jefe de la Delegación argentina sostuvo: "Siendo así, pueblos y naciones iestán por igual a merced de agresiones aparentemente incruentas que los precipitan a la violencia. Cabe preguntarse cuál es el grado de seguridad de un país en el que los últimos años se registran aumentos de los índices de mortalidad infantil y en donde existen sectores de la población que consumen menos proteínas que las que necesitan. Es rerdaderamente irrisorio pensar que pueda alcanzarse el éxito, confiando solamente en la suma potencia de las armas, cuando se va deteriorando el hombre, principal elemento de la defensa y de la razón misma de existix".

e. La Argentina habia observado un comportamiento opaco durante las reuniones de los países no alineados. A la diplomacia argentina no le interesaban estas reuniones por cuanto entendía que éste no exa un foro prioritario. Prácticamente se desconocia en el país la problemática de la no alineación a pesar de que ya en la región se habían producido significativos acercamientos al agrupamiento, v.g.: Perú, Chile, etc. La Argentina concurría a esas reuniones en calidad de observador, limitándose a explicar - a través de una diplomacia oficiosa - el problema de las Islas Malvinas. TaI como se había anunciado durante la campaña electoral, el gobierno justicialista solicitó su aclmisión al grupo durante la Reunión de Argel, solicitud que fuera aceptada.

f. Como consecuencia de la política supeditante que instrumenta- 
ron los gobiernos anteriores, las relaciones con los países socialistas decrecieron notablemente. Mientras que el porcentaje de nuestro comercio con esos países alcanzaba en 1964 el $14 \%$ del total de nuestras exportaciones y al $27 \%$ en materia cle importaciones, en 1968 prácticamente no se registraron exportaciones y las importaciones significaron sólo el 1,2\% clel total. En 1965 se exportó a los países socialistas por un valor de 205,5 millones de clólares y se importó por un valor de 34,2 millones de dólares. En 1968 esos valores habían descendido a 55,2 y a 14,2 respectivamente ${ }^{30}$. Esta situación, que iba en desmedro de los intereses argentinos, pretende ser revertida por la actual administración. La reciente gira de una misión argentina -encabezada por el Ministro de Economía- por los países socialistas tuvo por objeto aumentar el comercio y establecer acuerdos de complementación. Los resultaclos alcanzados fueron auspiciosos (según se desprende de las declaraciones oficiales) abarcando los acuerdos de coproducción los siguientes rubros: petroquímica, turbinas, maquinaria pesada, etc. La renta de automotores a Cuba (por más de 1.000 millones de clólares) constituye otro ejemplo de la apertura internacional argentina.

g. Dentro del marco de la política integracionista se destacan, en primer lugar, los repetidos viajes a la región de misiones argentinas integradas por empresarios y funcionarios del Estado. De esta manera se inicia una nueva política que, descartando el juridicismo y los formalismos tradicionales, apela a la flexibilidad y al pragmatismo, en un marco de intereses regionales comunes. En segundo lugar, si bien ya eran suficientemente conocidas algunas tesis de] Tte. General Perón referidas a la integración latinoamericana, los conceptos recientemente vertidos por el Presidente de la Nación al dejar inauguradas las Sesiones de la VI Conferencia de Cancilleres de los Países de la Cuenca del Plata, encierran una visión muy clara y precisa de un proceso caracterizaclo por la fluidez y el dinamismo. Dijo el Tte. General Perón:

"Hasta nuestros días la forma más común clásica de las relaciones internacionales ha sido la bilateral, la que contrapone los intereses de un Estaclo con los de otro Estado, de un Gobierno con los de otro Gobierno. No creo que la suma de esas relaciones bilaterales entre nuestros cinco países pueda ser el marco adecuado en que deban desarrollarse las relaciones económicas, sociales y culturales del área... Pero en un programa de desarrollo multinacional no debe interesarnos lo inmediato sino cuál va a ser la rentabilidad cle nuestras inversiones en un plan a mediano o largo plazo..."

30Del :"Y'carbook of International Trade Statistics”; Nueva York, N. Y., 1967 y 68. 
LA POLÍTICA EXTERIOR DEL BRASIL

La actual política exterior brasileña no puede ser comprendicla fuera del contexto político interno. Fiel a la añeja tradición en materia internacional, la adecuación entre ambas políticas es casi perfecta. De manera que los ciclos internos y las decisiones políticas que hacen a la esencia del modelo se ven inmediatamente reflejadas en la política exterior. El "toque personal" que a veces refleja la impronta de las personalidades gobernantes, sólo puede ser magnificado en función de la claridad metodológica, pero de ninguna manera se podrá sostener la existencia de cortes sustantivos.

A continuación se reseñan los grandes temas internacionales de la política exterior brasileña:

a) Las relaciones de poder dentro del régimen internacional. Brasil no ha dejado de manifestar su oposición a las características de excesiva rigidez que se observan en el régimen internacional. Algunos diplomáticos brasileños se han referido al tema aludiendo a "las tendencias hacia el congelamiento del poder mundial"3r. Lo que se cuestiona es el inmovilismo de la actual estructura internacional to que atentaría contra la permisibilidad internacional que exige y necesita el proyrecto externo brasileño. Brasil no se resignaría a asumir un rol de mero espectador, por el contrario, se ha encargado de repetir que desea participar en las grandes decisiones de la vida internacional.

Este será el objetivo de la diplomacia brasileña: PARTICIPAR. Afirmaba recientemente el Canciler brasileño: "Brasil ya no se supedita más a las lealtades automáticas". ${ }^{38}$

b) Algunas consecuencias que se desprenderían de la interacción tendencias internacionales $r$. s. proyecto exterior brasileño:

1. Desarme. El Brasil rechaza el Tratado sobre el Desarme por entender que el mismo "congela" una situación monopólica de poder que no tiene en cuenta los intereses de quienes todavía no han llegado a esos estadios del desarrollo. Esta política, que fue defivida con mayor claridad a partir de la gestión del General Costa e Silva, diferirá sustancialmente con la actitud asumida hasta 1964. El ex Canciller Santiago Dantas había afirmado: "Brasil comprende y

37Ver Araujo Castro, art. op. cit.

8sObservaciones formuladas al periodista Henry Raymont por el Canciller de la República de Brasil, Azeredo da Silveira, Jornal do Brasil, 17 de abril de 1974. 
aprecia los esfuerzos que tanto los EE.UU. y la URSS han ideado para alcanzar un condicionamiento adecuado entre el progreso del desarme por etapas y el establecimiento simultáneo de una inspección internacional eficaz". ${ }^{\text {so }}$

2. Negociaciones comerciales y financieras. Descle la perspectiva brasileña los instrumentos monetarios y comerciales creados al finalizar la II Guerra han dejado de constituir herramientas aptas para regular el orden internacional y mucho menos para contemplar los intereses de los países insuficientemente desarrollados. Afirmaba el Cancillex Gibson Barboza en el Discurso de apertura de la XVI CEGLA:

"Por más de un cuarto de siglo, venimos luchando por un orden económico que pueda eliminar las prácticas proteccionistas y discriminatorias características de los años anteriores a la Segunda Guerra Mundial... Sin embargo, los intereses nacionales distintos $y, a$ menudo, opuestos, acabaron por dar resultados bastante inferiores a los objetivos perseguidos".

En la misma pieza oratoria destacamos el siguiente párrafo: “. . El mismo razonamiento se aplica a la necesidad de atribuir fuerza legal al derecho de los países en clesarrollo a aplicar incentivos para la expansión de sus exportaciones". Allí se refleja una de las singularidades de la actual política exterior: cle acuerdo al foro se adecuará el tono y el lenguaje. A veces se hablará como "grande", otras no. Así por ejemplo, en la UNCTAD II, el Comité de Transporte Marítimo aprobó la ponencia brasileña que reclama el derecho de los países subdesarrollados a participar en las Conferencias Internacionales de Fletes que operan en sus circuitos de tráfico.

c) Relaciones Comerciales Internacionales. El comercio exterior es ahora más importante para Brasil que para los mismos EE. UU. Sólo los países de la Comuniclad Europea observan coeficientes más elevados en la participación del comercio exterior. La política que se desarrolla en este sector se inscribe dentro del "Plan de Acción Económica Gubernamental".

El comercio exterior brasileño registró en 1973 el mayor volumen de su historia: 12.214 millones de dólares. La participación de las exportaciones en el PBI ejemplifica el graclo de apertura de la estructura comercial brasileña: $12 \%$ contra $19 \%$ de Alemania Federal y $15 \%$ de Gran Bretaña.40

Descle 1964 se ha perfeccionado el complejo sistema de inçentivos

s9En Santiago Dantas, "Política Externa Independiente", Editora Civilización Brasileña, Rio de Janeiro, 1962.

40Del Jornal do Brasil, 16 de abril 1974, "Brasil, relaciones externas de transformación". 
fiscales - crediticios y cambiarios-. Mientras que en 1964 los procluctos manufacturados alcanzaban el 6,3\% de las exportaciones, en 1973 alcanzaban el 23,6\%. Se destaca asimismo el cambio operado en la dirección del comercio exterior, si bien los EE. UU. siguen sienclo el principal destinatario individual, la Comunidad Europea lo ha desalojado en términos brutos. También Japón ha pasado a ocupar un lugar clestacado dentro de la estructura del comercio exterior brasileño. La Comunidad Europea absorbió el $50 \%$ del intercambio (a pesar de competir el Brasil con las preferencias que la Comunidad otorga a sus ex colonias), Japón ocupó un porcentaje del $7 \%$ del intercambio total, ia ALALG un $9,8 \%$ y el COMECON un $4,3 \%$.

Este último dato merece un tratamiento más pormenorizado. Brasil ha demostrado saber clistinguir entre lo económico $y$ lo político. Será flexible en algunos aspectos y más duro en otros. Desde 1960 es el principal cliente latinoamericano de los países socialistas. Como proveedor sólo la Argentina lo superó en algunos años: 64-66. Esta relación no fue afectada por los cambios políticos ocurridos en 1964. Mientras que los gobiernos militares argentinos redujeron sus relaciones con el mundo socialista al mínimo, Brasil prácticamente las mantuvo para luego acrecentarlas. Otros indicadores de la importancia que se le atribuye al comercio con los países socialistas son: a) la creación de un organismo estadual encargado de las relaciones comerciales con el Este, el COLESTE; b) en 1966 se firmó un convenio con la URSS según el cual ésta se comprometió a utilizar el $25 \%$ de las divisas obtenidas de sus exportaciones al Brasil, en compras de productos manufacturaclos brasileños.

En 1973 el Ministro brasileño de Planificación, Reis Velloso, viajó a Moscú a los fines de estrechar los vínculos comerciales. En ese mismo año, el comercio con la URSS se duplicó. Además la URSS provee equipos turbineros - v. g. para la represa de Capivara-. La empresa soviética Soyuz provee normalmente petróleo al Brasil y es más, según el Jornal do Brasil (29-1-1974) un vocero de la empresa Soyuz no descartó la participación brasileña en la explotación del yacimiento gasifero soviético de Yakutia.

China Popular no ha quedado excluida de esta política pragmática. Mientras en 1964 las compras chinas no alcanzaban a los 200.000 dólares, en 1973 alcanzaron los 60 millones de dólares previénclose una compra china de 100 millones de dólares para 1974. Actualmente Pekín es el 3er. comprador de azúcar brasileño (Brasil sólo compra 300.000 dólares en el mercado chino) y', si bien Brasilia mantiene relaciones diplomáticas con Taiwan, xesulta sugestivo que desde hace dos años no ha acreditado embajador en la isla. Hasta el momento con Pekín.no existen relaciones diplomáticas, pero "algo está pa- 
sando". Recientemente viajó a Ghina una delegación brasileña de empresarios de la cual también formaba parte un diplomático brasileño. Finalmente, el Canciller brasileño invitó a una delegación china para que visite Brasil en agosto próximo.

Por: último anotamos también que el incremento de las relaciones económicas y comerciales con el exterior ha significado: a) inversión brasileña en el extranjero canalizada básicamente por BRASPETRO (la empresa estatal de petróleo explora o está en vías de hacerlo en: Libia, Argelia, Colombia, Rep. Malgache, Egipto e Irak) y también hacia los sectores de la industria textil y de calzados; b) una mayor participación de la flota nacional en el intercambio comercial. En 1966 la flota brasileña transportó el $12 \%$ y en 1969 el 35,2\% del total de los productos importados y exportados por Brasil.

d) América Latina. En el discurso pronunciado al asumir el Ministerio de Relaciones Exteriores del Brasil, el Canciller expresó: “...La primera responsabiliclad de la diplomacia brasileña es, obviamente, para con América Latina. Allí será nuestra tarea la cle explicitar las coincidencias esenciales que existen entre los países de la región, por encima y más allá de los desacuerdos ocasionales y de los traumatismos episódicos. Esa responsabilidad particular con los deberes que le son propios, deben ampliarse en todo el Continente..."

A continuación señalaremos algunos de los acuerdos logrados por Brasil en la región:

1. Recientemente suscribio un Acuerdo con Colombia dirigido a explorar los yacimientos carboniferos colombianos del Correjón. También se han firmado acuerdos entre Braspetro y Ecopetrol tendientes a explorar yacimientos petroliferos.

2. En julio de 1973 se firmó un acuerclo con Venezuela por el cual se estatuye la creación de una empresa mixta (Braspetro y la C.V.P.) con el objeto de explorar conjuntamente los yacimientos petroliferos de la zona fronteriza.

3. Braspetro y Petroperú han concluido los estudios de factibilidad para la exploración conjunta de los yacimientos petrolíferos limítrofes.

4. Se han firmado importantes convenios con Bolivia. Brasil comprará 40 millones de pies cúbicos diarios de gas boliviano. También existirá cooperación en materia de polos de desarrollo. El polo pre- 
visto deberá comprender un complejo siderúrgico; un complejo para la fabricación de fertilizantes y una fábrica de cemento. Con motivo de la firma de estos importantes convenios, el Presidente Geisel expresó en el discurso pronunciado en la ciudad cle Cochabamba: "Reconocemos y aceptamos, de manera inequívoca, las responsabilidades continentales".

5. Las relaciones comerciales con el Paraguay -actualmente estrechas como lo demuestra el hecho de que en los últimos cuatro años se incrementaron en un $70 \%$ - seguramente han de profundizarse como consecuencia de Ia firma de los documentos de Itaipú. Esta obra, el mayor complejo hidroeléctrico ideado hasta la fecha, inaugura una nueva etapa de colaboración entre ambos países.

e) Otros escenarios. Se lee también en el discurso del Canciller Azeredo da Silveira:

"...Elevado en las dimensiones de su economía y de su poder nacional, proyectándose en un mundo donde se estrecha la convivencia entre las naciones, no será posible al Brasil aislarse de lo que ocurxe en otras áreas, de las que emergen como nuevas urgencias en el África, en el Asia, en el Cercano Oriente y en el Asia..."

Dentro de este contexto nos interesará destacar lo relacionado al Continente africano. Habíamos visto que el tema había siclo anteriormente tratado durante la etapa de la denominada "política exterior independiente". La "Revolución Brasileña" no solamente no lo descarta sino que a su vez lo redefine.

El régimen de Lisboa encabezado entonces por el premier Caetano mantuvo hasta último momento una actitud intransigente respecto de no aceptar ningún tipo de negociaciones con los señores independentistas de sus colonias. Esta actitud no dejaba de ser mal vista en el Brasil en tanto $y^{\prime}$ en cuanto comprometía al país quitándole chance en ulteriores etapas negociadoras. Siempre con una perspectiva de largo plazo, hubo quienes en Brasil reclamaron una actitud dura para con la política colonialista de Caetano coherentes con la finalidad de conservar el prestigio dentro del complejo esquema político africano.

El derrocamiento del régimen lisboeta vino a facilitar enormemente las cosas para Brasil. Quedaba desligado de la pesada carga $y^{\prime}$ nuevamente puede abrigar esperanzas de convertirse en un interlocutor válido no sólo en los territorios portugueses del Atlántico sino también en otros países negros. El interés brasileño ya no se basa en razones de orden táctico o especulativo. Esto queda reflejado en la frase del Canciller brasileño que, refiriénclose à la política bra- 
sileña para con el Continente africano, dijo: "África es nuestra frontera atlántica". ${ }^{11}$

LA POLÍTICA EXTERIOR DE MÉXICO

Cuando la administración del Presidente Echeverría se hizo cargo del gobierno en 1970, en el orden interno comenzaban a vislumbrarse algunos síntomas de estancamiento económico. Esta constatación no deja de ser importante si se quiere desentrañar el "por qué" de la política exterior mexicana.

El desarrollo económico alcanzado por México durante la década del 60 (el "milagro mexicano") produjo una conciencia generalizada rayana en el "ufanismo". Numerosas apreciaciones coincidian en el pronóstico venturoso respecto del futuro. De manera que lo "revolucionario" y lo "institucional" pudieron convivir en la medida que no eran percibidos desafíos externos de importancia. La calma sociopolítica lejos está de provocar algún tipo de cambios en la política exterior. Por el contrario, la mejor "receta", en esos casos, aconseja no innovar. Esto, y decir que hasta el 70 en política exteriox la tradición histórica mantuvo total vigencia, es lo mismo.

$\mathrm{La}$ "memoria internacional" mexicana necesitaba remontarse al pasado, a Cárdenas o a los ya superados traumas históricos, en el caso de querer racionalizar o indagar acerca de los "por qué". La política exterior estaba al servicio de un sistema político que, habiendo surgido de una experiencia única en la región, conservaba hasta el presente un elevado margen de maniobra política. El consenso y la legitimidad aparecerían también como elementos atípicos para un Continente acostumbrado a otras prácticas políticas.

En este contexto, ¿cuál era el rol internacional del país? Ya hemos aranzado algunas ideas en el capítulo de "los antecedentes históricos". El modus vivendi y las "relaciones especiales" con los EE. UU. constituían el alfa y el omega de la diplomacia mexicana.

Veamos algunos indicadores de esta relación. El comercio exterior mexicano depende en un alto grado del mercado estadounidense. En 1964 sobre un total exportado de 904 millones de dólares, 608 millones se obtuvieron de las ventas al mercado estadounidense. En ese mismo año las importaciones se comportaban de manera similar; sobre un total de 1.240 millones de dólares, los productos norteame-

41Declaraciones formuladas por el Canciller de Brasil al periodista Henry Raymont en "Silveira analiza la acción del Brasil", Jornal do Brasil, 22 de abril de 1974. 
ricanos abastecieron por un monto cercano a los 1.030 millones de dólares. En 1969, sobre un total exportado de 1.380 millones de dólares, el mercado vecino absorbió 805 millones de dólares, en materia de importaciones sobre un total de 2.070 millones de dólares las estadounidenses proveyeron por un monto cercano a los 1.300 millones de dólares ${ }^{42}$. A estos indicadores se les deben agregar otros dos, no menos significativos, el $85 \%$ del turismo que visita México (sobre un total de 700 millones de dólares) es de origen norteamericano, y el $80 \%$ de la inversión extranjera tiene idéntica procedencia.

Al finalizar la década de los 60 aparecieron algunos indicadores no muy halagüeños. Algo estaba pasando. El crecimiento habia ido parejo al endeudamiento. Se le abría al modelo mexicano una compleja disyuntiva. ¿Cerrar las importaciones; aumentar el rol del Estado; proseguir con la política de endeudamientos crecientes? Estas eran algunas de las dudas que, desde el momento que constituían variables más o menos dependientes, influirian de una manera u otras sobre la politica exterior.

El año 1970 se presentaba bajo signo aparentemente adverso. EI déficit de la balanza comercial era ya insostenible, sólo el que se originaba con los EE. UU. había alcanzado a $\$ 65$ millones de dólares es decir un $83 \%$ superior con relación a 1969.43

Los caminos por donde debian transitar las soluciones no dejaban de presentar escollos. Vender las reservas no era muy conveniente y menos recomendable; detener la compra de insumos significaba receso y desocupación; renegociar la deuda podría constituir el inicio del sindrome deuda, servicios, deuda; redistribución a través de la inflación. Estas alternativas debian ser descartadas. Sólo quedaban dos respuestas, no excluyentes entre sí e incluso con posibilidades de interactuar positivamente: modificaciones estructurales y aumento de las exportaciones.

Ambas no dejaban de presentar facetas conflictivas y/o novedosas. La reformulación de ciertas estructuras económicas no podía dejar de lado a la política fiscal en un país en donde el índice de recaudación fiscal es uno de los más bajos de la región. En 1967 la recaudación fiscal significó el $7 \%$ del P.B.N. La estructura que podía ser afectada mayormente era, sin cluda, la que estaba en manos del capital extranjero $y^{\prime}$ de las grandes propiedades y capitales 'nacionales. Respecto de las exportaciones, el incremento necesitado no podía basarse en el mantenimiento de la anterior estructura y mucho menos en mantener los mismos destinatarios. Había que ampliar la composición del comercio exterior y era necesario abrir el espectro de países con los cuales se debía comerciar.

42Del "América en Cifras", 1970, OEA, Washington, D. C., 1971. 43 Fuente idem ant. 
Pensamos que estas opciones, unidas al tipo de personalidad $y$ a las ideas progresistas del Presidente Echeverría explican, en parte, el nuevo tono impreso a la política exterior mexicana.

Los elementos novedosos que se introducen en el esquema de gobierno interactuarán entre sí. La política reclistribucionista lesionará intereses $y$ ' seguramente interpondría obstáculos. El gobierno necesitará entonces demostrar, a través de algunos hechos, su voluntad y su compromiso respecto de la política de cambio.

La política exterior cumplirá una doble función. En primer lugar, abrirá nuevos mercados a la industria mexicana. En segundo Iugar se convertirá en un instrumento que deberá obrar como mecanismo de efectos demostrativos. Se tratará de atacar las injustas relaciones de poder internacional a la vez que se estará señalando que ellas ora medran, ora son consecuencias, de injustas estructuras. En última instancia, la política exterior obrará como "pedagoga" política de múltiple propósito: el externo y el interno.

De manera que en materia internacional México debía abandonar algunas de sus añejas tradiciones. Si el país realmente quexía desempeñar un rol en la región $y^{\prime}$ en el mundo debía olvidar, entre otras cosas, su perspectiva juridicista, el apego a las formas, el aislamiento respecto de su contorno geográfico (América Latina) y respecto de su contorno político (los países del Tercer Mundo). Por último, y sin dejar de lado su política tendiente a buscar el modus vivendi con su poderoso vecino, México debía también olvidarse de las "relaciones especiales".

Si bien anteriormente ya habían existido algunos obstáculos que se interpusieron a esta política "especial", v. g. el problema de la salinidad de las aguas limitrofes y la denominada "operación intercepción" (de la mano de obra migrante a través de la frontera), serán las consecuencias de la crisis económica intemacional las que en mayor grado provocarán inconvenientes a la relación bilateral EE. UU.-México.

La crisis monetaria y comercial internacional, la endeblez de ciertos mecanismos y métodos había llevado al mundo a manos de un nuevo proteccionismo. Esta tendencia llegará también a los EE. UU. quienes como reacción ante una situación económica no muy satisfactoria (las exportaciones norteamericanas por esos años habían debiclo ceder posiciones frente a la Comunidad Europea y a Japón) impondrán una serie de medidas económicas. El 15 de agosto de 1971, el Presidente Nixon sancionó: a) la inconvertibilidad del dólar; b) el congelamiento de los precios y las rentas por 90 días; c) la reducción del gasto público y d) la imposición de una sobretasa del $10 \%$ a la mayoría de las importaciones.

México, que ocupa el $5^{\circ}$ lugar entre los compradores de lọs EE. UU., 
debía replantear urgentemente su esquema económico. Con su otro "socio" en la clesgracia, Canadá, intentará negociar algún tipo de preferencias. La situación de Canadá está reflejada en estas cifras: en 1970 el $65 \%$ de sus exportaciones se dirigirán al mercado estadounidense y el saldo favorable al Canadá originado en ese intercambio alcanzará a 736 millones de dólares; en ese mismo año el superávit canadiense en balanza de pagos fue de 1.297 millones de dólares. ${ }^{44}$

Ante el fracaso de la negociación, México deberá responder a un desafío que distaba de ser fácilmente sujetable. La conciencia generalizada creía ver en el proteccionismo norteamericano y las consecuencias que el mismo ocasionaba para Mréxico, una analogía bíblica. Habia un "expulsado" o mejor dicho, una pareja de "expulsados". De allí en más estos constituían la "naturaleza caída" y, repitiendo el viejo drama, a partir de ese momento México debía ganar su subsistencia con el "sudor" de su propia imaginación y de su propio sacrificio.

Estos "shocks" resultan históricamente funcionales en tanto y en cuanto encuentran a un destinatario pletórico de voluntad y de imaginación. De lo contrario, sin creatividad y sin respuesta, se corre el riesgo de dejar de existir en términos de viabilidad y de vigencia histórica como nación.

Existió un curioso entrecruzamiento de demandas para el sistema político, unas internas y otras externas. Este tenía frente a sí, además de las responsabilidades inherentes, la posibilidad de introducir nuevos elementos y nuevas propuestas políticas, acentuando las variables "revolucionarias" en desmedro de las "institucionales".

En materia internacional la oportunidad de presentar la nueva imagen se presentará en la visita que el Presidente Echeverría efectuara en 1971 a las Naciones Unidas. Si bien ya otro presidente mexicano se había dirigido a la Asamblea, López Mateos, la exposición del Presidente Echeverría se destacó por las referencias directas que efectuó a los temas que interesan a los pueblos del Tercer Mundo. México fijó su posición referida a los principales problemas que afectan a los países en vías de desarrollo, sustentando su filosofia en la confianza hacia los mecanismos de solidaridad internacional, en desmedro de los tradicionales esquemas de la "política del poder".

Se inauguraba una nueva etapa en materia de política exterior. En esa misma sesión, al votarse el ingreso de China Popular a las Naciones Unidas $\mathrm{y}$ habiendo fracasado la tesis de las "dos Chinas", México apoyó con su voto a la propuesta albanesa.

4* Martín Guzmán Ferier, "El Canadá, política y economía". Archivo del F. C. E., México, 1973. 
Los siguientes son algunos de los temas preponderantes de la política exterior mexicana:

a) Desarme. En este aspecto México mantiene su actitud de apoyar cualquier tipo de propuesta que conduzca al desarme universal. En materia regional sigue auspiciando la necesidad de consolidar el Tratado de Desnuclearización Regional (Tlatelolco). Coherentemente con esta política anotaremos algunos puntos de interés:

1. En la XXVII Sesión de la Asamblea General de las Naciones Unidas, México apoyó la propuesta soviética de convocar a una Conferencia Mundial sobre el Desarme (China Popular y los EE. UU. se opusieron a la ponencia soviética).

2. En esta misma Sesión, México criticó a la URSS y a Francia por: negarse ambos países a suscribir el Tratado de Desnuclearización Regional.

3. En la XXVII Sesión criticará las prácticas dilatorias que se observan en la Conferencia del Comité de Desarme de Ginebra. Propone a la vez "reavivar" al Comité de Desarme de la ONU. Recordemos que en 1970 Brasil pidió la disolución del Comité y el traslado de estos temas a la Asamblea General.

4. En la XXVI Sesión de la Asamiblea de la ONU, México apoyó una propuesta de Ceylán dirigida a declarar al Indico una "Zona de Paz".

5. Durante los viajes realizados al exterior por el Presiclente Echeverría, éste insistió y reclamó, ante las potencias nucleares, la adhesión al Tratado de Desnuclearización Regional.

b) América Latina. La administración del Presidente Echeverría se ha caracterizado por el énfasis puesto en la política exterior dirigida hacia la región.

Con referencia a América Central, en 1971 el Banco Nacional de Comercio Exterior anunció el otorgamiento de créditos a mediano plazo que permitan el establecimiento de empresas mixtas con paxticipación minoritaria del capital mexicano.

México participa también de la Cámara de Compensación Centroamericana, del Banco Centroamericano de Integración Económica $y^{\prime}$ del Fondo Centroamericano de Estabilización Monetaria. Digamos que en 1972 las exportaciones de México a América Central constituyeron el $2 \%$ del total de su comercio exterior con un superávit de 31 millones de dólares. En 1971 la inversión mexicana en América Central alcanzaba a los 90 millones de dólares.

Con respecto al agrupamiento subregional Andino, la actitud mexicana se caracterizó por el dinamismo y la flexibilidad demostrada en el acercamiento al mismo. En 1972 se firmó el Acuerdo por el 
cual se creó la Comisión Mixta Andino-Mexicana la cual ya ha avanzado en importantes proyectos.

c) Relaciones Económicas Internacionales o las propuestas de "horizontalización" del régimen internacional. La adscripción definitiva de México en el contexto de los países denominados del Tercer Mundo se producirá en la UNCTAD III (abril de 1972). En el discurso del Presidente.Echeverría sobresalen, entre otros aspectos, la crítica al Decenio del Desarrollo y la propuesta que formulara a los países en desarrollo tendiente a unificar sus propios criterios (por ejemplo a través de reuniones periódicas y orgánicamente estatuidas del "Grupo de los $77^{\prime \prime}$ ). Finalmente, y resumiendo el ideario mexicano, el Presidente Echeverría esbozó lo que ha dado en llamarse "Carta de los Deberes y Derechos Económicos de-Ios Estados" que vendría a completar a la "Declaración Universal de los Derechos del Hombre".

Entre otros conceptos dijo el Presidente Echeverría:

"Este ha sido para gran parte de nuestros pueblos, un decenio de marginalidad creciente. Hoy es mayor el número de desempleados $y$ analfabetos que hace diez años... No se trata, exclusivamente, de una confrontación entre países ricos y pueblos desposeídos. Los intereses de las naciones avanzadas $y$ los de aquéllas que se encuentran en vías de desarrollo pueden $y$ deben ser convergentes. Queremos una toma de conciencia sobre la corresponsabilidad mundial del presente $y$ del porvenir".

UNA EXPERIENGIA DE SOLIDARIDAD REGIONAL: EL PACTO ANDINO

La experiencia andina ofrece, desde el punto de vista analítico, una riquéza poco común. Los elementos novedosos que el mismo introduce en la estructura del sub-sistema latinoamericano justifican entonces un tratamiento desde distintos planos de análisis.

a) Una de las dimensiones más importantes, y que ha sido insuficientemente explorada, es la que se refiere al tema de las viabilidades nacionales ${ }^{45}$. El problema hace referencia a la capacidad indivịdual que tiene un país -en función de sus propios recursos- de responder a los desafios internos y externos que a diario se le presentan. Las demandas internas se las puede agrupar en: 1) deseos de par-

"5Respecto del tema de las viabilidades nacionales debemos al Prof. Jaguaribe el reconocimiento por las' ideas que él nos aclaró en su obra: "Crisis y' alternativas de América Latiná: Reforma ó revolución", Paidós, Buenos Aires, 1972. 
ticipación; 2) redistribución; 3) bienestar; 4) modernización y desarrollo socio-político; 5) optimización y compatibilización de una alta tasa de desarrollo con un porcentaje alto de autonomía.

Respecto de las demandas (o más bien desafíos) externas, se destaca la necesidad de compatibilizar el fenómeno de la interdependencia con la subsistencia de la nación y del aparato estatal.

En la medida en que un país pueda responder positivamente y a corto plazo a estas demandas, nos encontraremos frente a un Estado nacional viable. El problema se presentará en términos de la prescriptibilidad casi dramática para aquellos Estados que no están en condiciones de responder positivamente y en corto plazo a las demandas que se le efectúan.

Para estos últimos habrá tres alternativas: 1) resignarse a una suerte de "invernación" internacional; 2) optar por la dependencia "racionalizada"; 3) avanzar en programas integrativos con audacia y espíritu solidario.

b) La presencia del agrupamiento subregional Andino vendrá a romper el tradicional sistema de equilibrio localizado. Este tuvo su origen en una diplomacia cuyos patrones de referencia no eran otros que los del "concierto europeo". Durante largos años el juego del equilibrio no dejó de tener justificaciones. Entre otras cosas, sin duda "educó" a nuestros diplomáticos ${ }^{46}$, y sirvió también a los intereses de la paz. Pero, como con todas las cosas, llegó un momento en que el sistema dejó de ser funcional. En vez de regularizar las relaciones diplomáticas o constituix algo así como "el termómetro internacional de la región", devino en mecanismo adormecedor. El juego resultó tan repetido que no daba lugar a la imaginación. Faltaba sin duda un sacudimiento o, lo que es lo mismo, un desafío. Alguien debía demostrar que se podía y se debía hacer algo. Y vaya que si lo hicieron.

c) El Pacto Andino inaugura en la región una nueva fórmula integrativa. Después de afirmarse durante años la necesidad de una política de integración que tuviera en cuenta los beneficios de "todos", los países andinos ejemplificarán en los hechos que ese objetivo además de deseable era posible. La política de "beneficios equilibrados"st constituye una prueba de ello.

d) Los países andinos adoptan una política de "personalidad"

16La idea nos viene de Claudio Véliz, "Cambio y continuidad: El Pacto Andino en la historia contemporinea", en Estudios Internacionales, № 16.

47Félix Peña, "El Grupo Andino: un nuevo enfoque de la participación internacional de los paises en desarrollo", en Estudios Internacionales, No 22, abriljunio 1973 . 
frente a terceros, ya sean estos Estados o empresas transnacionales. La Decisión 24, referida al capital extranjero, y el régimen estatuido para la transferencia de tecnología, constituyen algunos de los indicadorés de una nueva práctica internacional.

e) Finalmente, los países andinos tratan de demostrar que todavía es factible compatibilizar intereses nacionales e intereses regionales, autonomía y bienestar general.

PARTICIPAGIÓN INTERNACIONAL Y AUTONOMÍA EN LAS DEGISIONES

En este capítulo trataremos de avanzar algunas ideas respecto de cuáles son los indicadores del rol de la potencia intermedia y cuáles los de las que aspiran al rango de potencia. Las potencias intermedias ¿pueden aspirar a participar en la jerarquía del régimen internacional?

¿Cuál es el significado de una política "participacionista"? Xa respuesta está condicionada, en gxan medida, por las características del régimen internacional. Resulta entonces necesario definir ese marco de referencia. Con todas las limitaciones del caso, nuestro marco se define por un sistema internacional en donde existe una estratificación con "grandes", "meclianos" y "pequeños". Dentro de los "grandes" hay algunos más "gxandes" que otros. Estos últimos, justamente, definirán el sistema como una aristocracia de Estados con tendencias a una profunda diferenciación entre ellos y a un progresivo deterioro de las posibilidades de acceso a dicho círculo.

"Participacionistas" serán entonces aquellos proyectos políticos que se propusieran las siguientes metas:

a) Para los que están clentro de la "aristocracia de los grandes", tratar de acortar -o por lo menos mantener- la brecha que los separa de los "más grandes". Entre ellos también existen diferencias. Un elemento decisivo para las posibilidades "participacionistas" de estos "fuertes no tan fuertes" radica en el tipo de viabilidad nacional requerida. Así, los europeos debieron jugar una estrategia que maximiza la integración. Otros países - como China Popular- podrán optar por la vía solitaria. Un ejemplo de feliz percepción de las fuerzas internacionales en pugna desde una perspectiva de un "fuerte no tan fuerte", es Ia política gaullista. Excluido originariamente de los "más grandes" de la aristocracia (en Yalta), aceptado luego como un socio menor, debe maximizar su: viabilidad nacional a través de una integración "pura". Esto quiere decir que no puede permitir que 
entre en ella alguien que no haya definido el "por qué" de esa integración (Gran Bretaña). A pesar de la cluda respecto de la significación de Gran Bretaña para la pureza integrativa, en el orden bilateral nacla impicle una política cooperativa (Proyectos Concorde y Jaguar). El problema de la pureza se presenta respecto del clispositivo maximizador -la integración- en donde sí será necesaria una gran selectividad.

Respecto del caso China, siempre queda en pie la duda referida a sus verdacleras intenciones. Su lógica internacional ¿coincide con la occidental? Los valores que privilegia la racionalidad china ¿coinciden necesariamente con los de Occidente?

b) Para los que están fuera de la "aristocracia de Estados", las alternativas son variadas. ¿Se puede participar a través de otros? Pensamos que no. De manera que jugar al "mejor amigo del más fuerte" no tiene senticlo. ¿Se puede participar en el mediano plazo aislándose en el plazo corto? Pensamos que tampoco. Esto tal vez fue factible cuando el "tempo" era más lento. Además çhasta qué punto el "provincialismo" voluntario constituye una alternativa viable en un mundo interdepencliente?

Quedan finalmente por analizar clos vías de participación para quienes actualmente no integran la ."aristocracia cle naciones.". El rol de potencia intermedia o directamente el de potencia.

Potencias intermedias. A pesar de existir un sinnúmero de definiciones respecto de "quiénes" y "cómo" son las potencias intermedias, pensamos que el elemento que las distingue y define es el ámbito en donde actúan y los alcances de su poder de influencia. Desde esta óptica, potencia intermedia es la que juega un papel regional, y cuyas aspiraciones no van más allá de los límites geográficos de su propio subsistema regional.

Definido el ámbito de influencia falta hacer lo mismo con la dimensión de su rol, siempre dentro de los parámetros forzosamente arbitrarios que nos fijáramos anteriormente.

Dos preguntas nos allanarán el camino: ¿Cómo se autopercibe y en base a qué razonamientos optó por ese rol? ¿Cómo la perciben los "grandes" y los "pequeños"?

Autopercibirse o autoproponerse un rol internacional con caracteres de intermedio dependerá nuevamente de varias circunstancias. En primex lugar cabe citar el más racional de los fundamentos: la relación viabilidad-recursos. Un país que posea un alto grado de viabilidad nacional $y$ de recursos propios como para definir un proyecto societal caracterizado por introducir esquemas de modernización y desarrollo político, autogenia en su sistema de decisiones y un 
-perfil nacional más o menos definido, estará en posibilidad de plantearse para sí un rol internacional intermedio.

Otra circunstancia - más bien subjetiva - radica en los valores que la sociedad y el Estado en cuestión privilegien. Esas naciones deberán juzgar la calidad de los valores ponderados por los "grandes", pudiendo coincidir o no con los esquemas de la política del poder. Podrán tener una visión "horizontal" o "vertical" del régimen internacional. En este último aspecto existe una curiosa propensión: quien en el sistema político interno opta por las relaciones "verticales" en el sistema internacional privilegiará también esos esquemas, y viceversa, según sea el caso del país que se trate.

Respecto del cómo "otros" perciben a la potencia intermedia, digamos que la variable solidaridad (rechazo de la política del poder) nos ayudará a detectar las percepciones que los demás efectúan respecto de las potencias intermedias.

Comenzaremos por la percepción que realizan los "más grandes". Distinguiremos según se traten de "potencias intermedias solidaristas" (que privilegian los esquemas de solidaridad) o de "potencias intermedias no-solidaristas" (las que privilegian la política del poder).

\section{a) Potencias intermedias solidaristas}

Si bịen la estructura ideal del régimen internacional que ambos sostienen los "más grandes" y este tipo de países "intermedios" es disímil, la adscripción de los primeros a los esquemas del poder, provoca en ellos una actitud de despreocupación respecto de los segundos. Como no creen en valores ni en la fuerza de la solidaridad, ignorarlas será una manera de ser coherentes consigo mismos. ¿Cuáles serán entonces los "deberes" de los "más gxandes" para con estos países que para ellos constituyen unos especímenes utopistas? Básicamente respetarlos.

Esto quiere decir que en algunos casos se les dará ayuda, sobre toclo si constituyen países estratégicos. Subyace también bajo esta política de ayuda un sesgo de temor. Como los "más grandes" compiten entre sí, no pueden dejar de preveer que si maltratan a estas potencias intermedias, ellas podrán acudir al adversario (sin que esto necesariamente signifique adscribirse a su órbita).

Por último, deberán aceptar como uno de los costos de la despreocupación, que estas potencias intermedias solidaristas usen algunos foros internacionales como plataforma de presentación respecto de la comunidad internacional y de crítica - a veces muy dura- a la conducta de los mismos "más grandes". En estos foros, los "inter- 
medios" se liberan de pesadas cargas emócionales acusando --en esta especie de tribunal internacional- las prácticas de: los "más grandes" que ellos consideran perniciosas para la comunidad.

\section{b) Potencias intermedias no-solidaristas}

Estas potencias pueden resultar peligrosas para los "más grandes". Constituyen los inayores "antidescongelantes" del régimen internacional. En consecuencia atentan contra sus intereses hegemónicos. Adémás tienen entre sí curiosas coincidencias: observan el 'mismo origen (cuestionadores); ambas privilegian una estructura "verticalista" del régimen internacional; sus métodos son idénticos. 'Las potencias intermedias no-solidaristas observan una voluntad política exultante (como antaño los "más grandes") y, finalmente, al igual que los "más grandes" en el pasado, los que hoy luchan por participar pretenden reemplazar a los actuales integrantes de la "aristocracia de estados".

Los "más grandes" procederán en consecuencia. En realidad, cuando tratan de mantener la actual relación de fuerzas internacionales, lo que realmente hacen es marginar a estos aspirantes intermedios. ¿Acaso el Tratado sobre el Desarme no es un instrumento pensado por los "más grandes" en desmedro de estas potencias intermedias nosolidaristas?

Debe también destacarse que cuando el "más grande" subdelega responsabilidades en estos intermedios, él lo hace sólo por razones de coyuntura, puesto que a largo plazo sus intereses son divergentes. Los denominados países "llaves" lo son en tanto se conforman con serlo, pero no pueden aspirar a más.

¿Cómo ven a las "potencias intermedias no-solidaristas" los que formando la "aristocracia" no alcanzan a ser "más grandes"? Nuevamente será necesario distinguir. La primera cuestión se refiere al tipo de potencia intermedia (solidarista o no) y la otxa se refiere a las características intrínsecas del "perceptor".

Un perceptor que integra la "aristocracia" pero que se siente débil (generalmente son países que "fueron algo" y han dejado de serlo) es muy difícil que pretenda escalar posiciones en la pirámide internacional. Estará conforme en ser considerado miembro de la "aristocracia" (generalmente su ubicación en la estratificación internacional le favorece en el sentido que los indicadores en base a los cuales se estatuyen los roles, generalmente están desactualizados). El juego de estos "fuertes no tan fuertes" de ninguna manera enfrenta a los "más grandes", es más, hasta llegan a identificarse con alguno de ellos.

¿Cómo percibirán estos actores a las potencias. intermedias solidaristas? De buen tono. Existen coincidencias respecto de algunos 
valores que ambas privilegian, v.g.: democratismo, calidad de vida, justicia, etc. Lo que estos soliclaristas clemandan es algo conocido y valorado por paises que han llegado al "velfare state". De manera que en numerosas oportunidades, estos "aristócratas" clefenderán Ios reclamos de las potencias intermedias solidaristas con el mismo empeño que pondrán de manifiesto en no apoyar a las potencias intermedias no-solidaristas, las que obviamente son mal vistas.

Distinta percepción tendrá un país que, ocupando un lugar en la "aristocracia de Estados", trata de ascender posiciones. Es decir que se enfrentaxa con los "más grandes".

- Este tipo de "aristócrata" posee también una lógica "descongelante". 'Sé siente en gran "medida afectado y marginado. Constituyen estos países una especie de "anti-élite intemacional" que no vacilan en movilizar a ottos cuestionadores tras sus objetivos. Esta "anti-élite internacional" percibirá a las "potencias intermedias no-solidaristas" como aliados circunstanciales. Las coincidencias harán relegar para el futuro cualquiera de los temas conflictuales que se le pudieran presentar entre ellas.

Respecto de la. percepción que éstos tienen respecto de las potencias intermedias solidaristas, sencillamente no les preocuparán. Más aún, en algunas circunstancias sus intereses coincidirán, v. g., cuando los solidaristas: critican los abusos de los "más grandes"

¿Cuál es la percepción que tienen los "pequeños" respecto de las potencias intermedias? La pregunta se referirá básicamente a las potencias intermedias no-solidaristas puesto que, para con las solidaristas, los "pequeños" no tienen problemas. Es más, a veces las percibirán como aliadas.

Los países pequeños tienen razones muy valederas para desconfiar de las potencias intermedias no-solidaristas. En tanto que sus visiones del mundo difieren, mal puede haber cooperación. Veamos "algunas características de la relación vis à vis "potencias intermedias no-solidaristas v.'s. países "pequeños".

a) Las potencias intermedias privilegian las relaciones "horizontales". ("descongelan" para luego "congelar").

b) En la zona: de influencia directa de las "intermedias", éstas no se llegan a comprometer del todo con los problemas de la región. Su aćtitud será ambivalente.

c) Dentro del contexto regional, el mayor desafío para un país "pequeño" será el que proviene de este "intermedio" que busca aumentar su poder. 
d) En materia de cooperación y' ay'uda y a pesar de no aceptar ni los usos ni los abusos de los "más grancles", al pais "pequeño" le convendrá más la ayuda que proviene de éste $y^{\prime}$ no la que eventualmente le prometa el intermedio no-solidarista (entre otras cosas, la ay'uda del "más grande" es más "barata").

e) Todo intento de los países "pequeños" dirigido a maximizar su poder por la vía comunitaria es mal visto por las potencias intermedias.

Tan ciertos son estos intereses objetivamente encontrados que, históricamente, se observa un patrón de conducta internaciónal único entre ambas partes. En última instancia, los "pequeños" están más cerca de los "más grandes" que de estos aspirantes. La historia no escatima ejemplos en donde los "pequeños" han tratado de destruix (políticamente) a estos intermedios. ¿Acaso el Imperio Otomano no fue una de sus víctimas?

Por último, ¿cuáles son las características que definen a quien juega a aspirante de "potencia"? En el presente operará como una "potencia intermedia no-solidarista" dado que para llegar a ser miembro de la "aristocracia de estados" no existe una vía "directa".

Pero desde ya se comportará como lo hacen los "más grandes". Mientras que las "potencias intermedias solidaristas" deberán preocuparse por los fines y por los medios, la aspirante a potencia sólo aspirará a avanzar en pos de sus fines, sacrificando, a veces, los medios. 